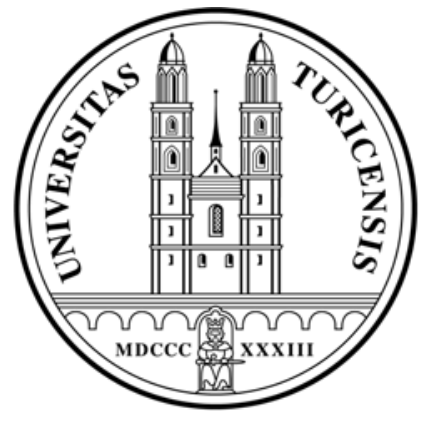

Institute for Empirical Research in Economics

University of Zurich

Working Paper Series

ISSN 1424-0459

Working Paper No. 457

To Shape the Future: How Labor Market Entry

Conditions Affect Individuals' Long-Run Wage Profile

Beatrice Brunner and Andreas Kuhn

November 2009 


\title{
To Shape the Future: How Labor Market Entry Conditions Affect Individuals' Long-Run Wage Profiles
}

\author{
Beatrice Brunner, University of Zurich* \\ Andreas Kuhn, University of Zurich and IZA
}

November 2009

\begin{abstract}
We study the long-run effects of initial labor market conditions on wages for a large sample of male individuals entering the Austrian labor market between 1978 and 2000. We find a robust negative effect of unfavorable entry conditions on starting wages. This initial effect turns out to be quite persistent and even though wages do catch up later on, large effects on lifetime earnings result. We also show that initial labor market conditions have smaller and less persistent effects for blue-collar workers than for white-collar workers. We further show that some of the long-run adjustment takes place through changes in job-mobility and employment patterns as well as in job tenure. Finally, we find that adjustments at the aggregate level are key to explain wages' adjustment process in the longer run.
\end{abstract}

JEL classification: E3, J2, J3, J6, M5

Keywords: labor market cohorts, initial labor market conditions, long-run wage profiles, persistence of labor market shocks, unemployment, business cycle

\footnotetext{
${ }^{*}$ We thank Joshua Angrist, Johann Brunner, Marcus Hagedorn, Martin Halla, Christian Hepenstrick, Helmut Hofer, Bo Honoré, Rafael Lalive, Michael Lechner, Andrew Oswald, Steven Stillman, Till von Wachter, Rudolf Winter-Ebmer, Andrea Weber, Tobias Würgler, Josef Zweimüller, various seminar participants in Engelberg, Linz, Weggis and Zurich, as well as participants at the 2009 Annual Meeting of the Austrian Economic Society in Linz, the 2009 Spring Meeting of Young Economists in Istanbul and the 15th International Conference on Panel Data 2009 in Bonn for helpful comments and suggestions. Financial support by the Austrian Science Fund is gratefully acknowledged (National Research Network: "The Austrian Center for Labor Economics and the Analysis of the Welfare State"). "To Shape the Future" is borrowed from the title of a track by Optical. Contact: Institute for Empirical Research in Economics, University of Zurich, Mühlebachstrasse 86, 8008 Zurich, Switzerland; bbrunner@iew.uzh.ch; kuhn@iew.uzh.ch.
} 


\section{Introduction}

Young individuals who have completed their training and plan to enter employment may find themselves faced with very different economic conditions. Some young workers may be lucky, entering into the labor force while the economy is doing well and unemployment is low, and may easily find a good-paying job. Some others may not be so lucky, finding themselfs forced to start their labor market career in a recession, faced with much less promising career prospects. These unlucky individuals will probably receive much lower initial wage offers compared to when they had entered in a boom and may never make up with their luckier counterparts, and they presumably will suffer from persistent losses in lifetime earnings.

In this paper, we present empirical estimates of the long-run effects of business cycle fluctuations, captured by cyclical fluctuations in local unemployment rates, on young worker's wages and give an empirical assessment of the associated loss in lifetime earnings from entering the labor force during a recession. Indeed, previous research has shown that the early years in a worker's labor market career are of special importance (Gardecki and Neumark, 1998; Neumark, 2002). For example, Murphy and Welch (1990) estimate that almost $80 \%$ of all wage increases accrue within the first ten years of labor market experience. It has also been shown that movements across jobs are considerably more likely at the beginning of a worker's career than later on (Topel and Ward, 1992). Further, Raaum and Roed (2006) show that individuals who face particularly depressed local labor market conditions at the time they finish school are at a higher risk of unemployment not only when young but also in later years. ${ }^{1}$ Overall, the empirical evidence thus suggests that any disruption at this early stage of one's labor market career may translate into considerable long-run wage effects. Also, because individuals at the transition from education to work are eventually hurt most by aggregate labor market shocks, it is these young workers who are often the main focus of labor market policies which aim to cushion labor market shocks (Ryan, 2001). However, although we focus on individuals newly entering into the labor force we believe that such evidence is informative about the persistence of labor market shocks as well as about the reasons for such persistence more generally.

Indeed, there is growing empirical evidence on the persistence of negative wage effects from economic conditions at the time of labor market entry, which eventually will accumulate to

\footnotetext{
${ }^{1}$ Similar results for British and Japanese workers are reported in Burgess et al. (2003) and Kondo (2007), respectively.
} 
large overall losses in lifetime earnings. ${ }^{2}$ Oreopoulos et al. $(2006,2008)$ in detail explore the effects of entering the labor market during a recession on earnings and job mobility, using data on Canadian college graduates who enter the labor market between 1982 and 1999. They find a substantial initial wage penalty of about $9 \%$, which fades to zero after the first decade of a worker's career only. They also find that the adjustment process works through an increase in job mobility which in turn is driven by workers moving to better paying firms. Moreover, they find that higher skilled graduates suffer less because they switch to better firms more quickly while lower skilled entrants are permanently affected by bad entry conditions. Similarly, Kahn (2009) focuses on male college graduates in the United States who were graduating sometime between 1979 and 1988. She finds the group graduating in the worst economic situation to suffer from a wage loss of up to $13 \%$ each year over the first twenty years of their labor market career, relative to those graduating in the best initial conditions. Similar results are reported in Oyer (2006). He shows that Ph.D. students in economics, graduating in times when the demand for economists is high, are considerably more likely to get a position at one of the top universities in the United States. Similarly, he finds that those MBA students who complete their training in a recession suffer from negative effects on wages (Oyer, 2008). Again, the long-term effects on income appear to be caused by the fact that workers entering the labor market at different conditions are hired by different employers. Thus, particularly among highly educated individuals for whom the transition in and out of attractive positions is very low, it appears as if the entry job matters a great deal for the future career. ${ }^{3}$ Overall, all these

\footnotetext{
${ }^{2}$ Even though it has been known for a while that the distinction between cohort effects and cyclical and life-cycle patterns is conceptually important (e.g. Freeman, 1981), it is only more recently that the empirical literature began to focus directly on the relation between wage differentials across labor market cohorts and initial labor market conditions. In contrast, the short-run association between the local unemployment rate and wages or, more generally, between local labor market conditions and real wages has been extensively studied since the pioneering work of Blanchflower and Oswald (1990), who find wages and local labor market conditions to be negatively correlated. This negative association turns out to be a very robust empirical pattern and has been shown to exist for a wide range of countries using very different sources of data and different empirical specifications. This is documented in the survey by Nijkamp et al. (2005), for example, which reports an average elasticity of real wages with respect to the local unemployment rate across countries of about -0.10 . As these studies focus on workers of different age and therefore at very different stages of their labor market career, one might expect even larger effects when focusing on labor market entrants only, as starting wages are found to be considerably more flexible than incumbent workers' wages.

${ }^{3}$ One main concern as regards the validity of these results is that schooling and first entry into the labor force may both be endogenous because individuals may choose to stay in school or get involved with further training when faced with high unemployment and low starting wages. Indeed, several studies find that enrollment rates are high when unemployment is high and opportunity costs of schooling are low (e.g. Card and Lemieux, 2000; Dellas and Sakellaris, 2003; Gustman and Steinmeier, 1981). In line with these results, both Kahn (2009) and Oreopoulos et al. $(2006,2008)$ find the duration of schooling to be endogenous. Both tackle the endogeneity problem by instrumenting the business cycle indicator at the time of labor market entry with either the rate
} 
studies point to substantial losses in lifetime earnings from entering the labor market during a recession as opposed to entering during a boom. ${ }^{4}$

However, all the above mentioned studies focus on the flexible labor markets of either Canada or the United States and on highly skilled workers only. One may thus wonder whether the results carry over to other, less flexible, labor markets and to less skilled workers. Empirical evidence for other countries is scarce, but broadly similar results are reported in Kwon and Meyersson Milgrom (2007) for the Swedish labor market. They find that workers entering the labor market in a period of recovery are paid lower starting wages, but that they also get promoted more quickly and therefore (but somewhat counter-intuitively) end up with wages higher than average in the end. Also, negative effects of initial labor market conditions are not to be confined to highly skilled workers. The paper Genda et al. (2009) is especially interesting in this respect because it studies the effects of initial conditions separately for more and less educated men in a comparison between Japan and the United States. The authors find negative effects of initial conditions for higher skilled workers in both countries, but they only find effects for Japan as regards lower skilled workers. They argue that both the hiring system and employment protection drives the persistence of the effects for Japanese, while the market for less skilled workers in the United States may indeed be quite close to a competitive market. Kondo (2008) again uses data from the U.S. and finds that the initial effect of entering the labor market during a recession is less persistent for both less skilled workers and workers with weak labor market attachment, a finding in contrast to the result from Oreopoulos et al. (2008) but in line with the results from Oyer (2006, 2008).

In this study, we use social security records from Austria to study the long-run impact on wages of unfavorable entry conditions. ${ }^{5}$ Our sample consists of male workers who have entered into the labor force for the first time sometime between 1978 and 2000, a period covering several booms and busts. After individuals' first entry into the labor force, we can follow their careers for at least 5 and up to 27 years. Because the data contains comprehensive and very accurate information about annual earnings and daily employment histories, it is almost perfectly suited

\footnotetext{
prevailing at a lower age or the rate in the predicted year of graduation.

${ }^{4}$ Besides these substantial effects on earnings, recent research presents the intriguing result that growing up during a recession may even change individuals' beliefs about the determinants of economics success (Giuliano and Spilimbergo, 2009).

${ }^{5}$ Hofer and Weber (2002) and Raferzeder and Winter-Ebmer (2007) provide a more general empirical assessment of wage mobility and Stiglbauer et al. (2003) of job turnover in the Austrian labor market.
} 
for this kind of research exercise. Unlike most other studies, we direct our attention not to high-skilled workers but to workers with vocational training only. While this is partly driven by data limitations, focusing on lower skilled workers also has some conceptual advantages. On the one hand, we believe that this restriction reduces the problem of endogenous entry into the labor force. On the other hand, it arguably also minimizes the role played by job promotions which we do not observe in the data because the data contain no information about job levels. Consistent with previous evidence, we find large and persistent effects of initial labor market conditions on workers' real wages. Specifically, we find that the elasticity of wages with respect to the initial unemployment rate is $-6.2 \%$ in the year of entry and then shrinks to about $-1.5 \%$ five years later, resulting in substantial overall losses in workers' discounted lifetime earnings.

Several distinct mechanisms have been put forward to explain persistent wage differentials across different labor market entry cohorts. It seem helpful to us to first distinguish between external market forces and internal labor markets as in Lazear and Oyer (2004), and we believe that both of them are likely to be important in explaining persistent cohort wage effects. Specifically, we think that the empirical finding of wages of newly entering workers being more responsive to fluctuations in the business cycle than incumbent workers' wages as supportive of such a conceptual distinction. ${ }^{6}$

The most obvious candidate explanations with respect to external markets are, in our view, based on search frictions (Mortensen, 2003) or on a more general presumption that firms have some discretion in setting their wages, either because firms have monopsony power (Manning, 2003) or because there is rent-sharing between firms and workers stemming from, for example, product market imperfections (Guadalupe, 2007) or technical innovation (van Reenen, 1996). More specifically, von Wachter and Bender (2008) find that workers with relatively high entry wages have larger and more persistent earnings losses at job displacement, arguing that this may be interpreted as evidence for temporary rent-sharing. While search models clearly emphasize workers' mobility across jobs as a potential adjustment mechanism to initial wage shocks, we think that the accumulation of human capital can simply be viewed as the flip side of worker

\footnotetext{
${ }^{6}$ The effect of the local unemployment rate on starting wages of newly entering workers that we find is much higher than existing estimates for Austria focusing on both new entrants and incumbent workers (see appendix B). Qualitatively similar results are reported in Haefke et al. (2008) for the U.S. Related evidence on the wage cyclicality of job movers vis-à-vis job stayers is given in (e.g. Devereux and Hart, 2006). von Wachter and Bender (2008) find that differences in entry wages within firms fade over time, which points to the importance of aggregate forces, at least in the longer run. This result in turn is in line with the evidence presented in Lazear and Shaw (2008), underlining the importance of external market forces.
} 
mobility and must therefore also be considered as part of a potential explanation. Indeed, most of the studies already mentioned acknowledge the potential importance of mobility in explaining differences in long-term wage patterns across labor market cohorts. ${ }^{7}$

However, the internal economics of the firm also appear to be important, at least for incumbent workers, and may thus also be important to explain wage differentials between labor market cohorts. Acknowledging some role of explanations based on the internal economics of firms foregrounds the potential impact of formal salary systems and firms' rules regarding individuals' job mobility and career paths within firms. ${ }^{8}$ In any event, it seems plausible to us that employers differ with respect to their internal economics and that such differences may be relevant in explaining how wages respond to shocks in external conditions, even though recent research argues that most of the observed wage distribution appears to be driven by worker heterogeneity. ${ }^{9}$ While there is a myriad of mechanisms that may potentially be useful in explaining cohort effects in wages, only a few studies have tried to explicitly explain persistent cohort effects in wages. In the contract model of Beaudry and DiNardo (1991), workers starting a job in times of high unemployment accept lower long-run wages initially, but then wages are bargained over again as soon as economic conditions strengthen. Gibbons and Waldman (2006) propose a model which combines job assignment, accumulation of task-specific human capital while on the job, and employer learning about workers' productivity can generate persistent cohort effects in wages. Their main argument is that workers entering in a recession enter low-level jobs with a higher probability and accumulate skills that are of less value, relative to

\footnotetext{
${ }^{7}$ Oreopoulos et al. (2008) find that mobility across firms and industries plays an important role in explaining why cohorts' wages converge in the longer run. They further find that the highly skilled workers quickly move to better paying firms while the lowest skilled workers suffer from permanent earnings losses because they are permanently down ranked to low paying firms. Similarly, Bowlus (1995) finds that job tenure is somewhat lower for jobs started during a recession and Bachmann et al. (2009) find that workers entering in a recession have a higher propensity to move across jobs. Relatedly, Kwon and Meyersson Milgrom (2007) find that those who entered during a recession get more quickly promoted. In contrast, Kahn (2009) finds that those workers who have entered in a recession have slightly higher job tenure, pointing rather to lower mobility (but accumulation of more human capital), and Saks and Wozniak (2007) find that regional mobility is highest when unemployment is low.

${ }^{8}$ Clearly, the most prominent (although not the first one) study based on personnel records is the one by Baker et al. (1994a,b) on managerial workers from a U.S. service industry firm. Other interesting empirical studies based on personnel records from single firms include Dohmen (2004), Flabbi and Ichino (2001), Seltzer and Merrett (2000), and Treble et al. (2001). Recent international evidence on the pay structure both between firms and across workers within firms is given in Lazear and Shaw (2008).

${ }^{9}$ For example, Abowd et al. (1999) show that a large fraction of the observed inter-firm wage dispersion can be accounted for by unobserved worker heterogeneity and that firm fixed effects play a minor role only. See Gruetter and Lalive (2009) for an analysis based on Austrian data with similar qualitative results.
} 
workers entering the labor market in a boom. ${ }^{10}$

An additional, final explanation rests on the argument that the composition of entry cohorts changes over the business cycle. As has been argued by Bils (1985), and more recently by Solon et al. (1994) and Blundell et al. (2003), endogenous (timing of) labor market entry over the business cycle will result in compositional changes across different entry cohorts. For example, it may be the case that only the better skilled workers find a job in times of high unemployment, resulting in compositional effects because there will be relatively more skilled workers in entry cohorts which start their career in a recession than in cohorts entering the labor market in a boom (see also footnote 3 ).

We provide some empirical evidence on each of the three main mechanisms mentioned above in this study. First we show that our results are not driven by sample selection over the business cycle, but that they rather yield a lower bound of the true effects. Second, we provide some suggestive evidence on the importance of the internal economics of the firm with respect to the long-run adjustment of wages. This additional analysis is based on individuals' initial occupation, i.e. blue- versus white-collar occupation, a characteristic that is easily and very accurately observed in the data and which is arguably linked to the prevalence of features internal labor markets such as formal salary systems or career paths and their importance in determining wages. Specifically, we show that it is white-collar workers who suffer from large and persistent negative effects while initial effects for blue-collar workers are much smaller and quickly fade away in the years following labor market entry moreover. This finding is consistent with Schwerdt et al. (2009), who find that, in the long run, earnings losses following job displacement are much larger for white-collar workers than for blue-collar workers in Austria. One potential explanation for this finding is that monitoring is more difficult and/or more costly for white-collar occupations and that therefore incentive schemes are more prevalent in white-collar occupations. Third, and finally, we show that initial labor market conditions not only affect starting wages but also have an impact on individuals' mobility prospects in the short run and thus on individuals' accumulation of human capital. We further emphasize that the business cycle itself is an important part of explaining the adjustment process of wages in the longer-run, as both mobility and employment patterns seem to be mainly driven by

\footnotetext{
${ }^{10}$ In support of such an argument, Devereux (2000) finds that workers are assigned to tasks that need less skills during a recession. On the specificity of human capital, see Neal (1995) and, more recently, Sullivan (2009).
} 
changes in aggregate economic conditions.

The remainder of this paper is structured as follows. In section 2 we present our data source and detail how we have selected our sample of male labor market entrants. Section 3 shows entry cohorts' long-run wage profiles and discusses our econometric approach for estimating the long-run wage effects of initial labor market conditions. Moreover, we discuss the sensitivity of our results with respect to sample selection, functional form and usage of different unemployment rates. In section 4 we study four specific explanations for the observed sluggish wage adjustment in the long run. Specifically, we study the potential impact of sample selection over the business cycle, the role of mobility and human capital accumulation, the importance or the initial employment status and firm size as well as the role of the business cycle. Section 5 sums up and concludes.

\section{Data and Sample}

\subsection{Data Source and Key Variables}

We use social security records drawn from the Austrian Social Security Database (ASSD), which is described in more detail in Zweimüller et al. (2009). The ASSD covers the universe of Austrian private sector workers from January 1972 until December 2005. Because the data are collected with the purpose of administering and computing future old-age pension benefits they contain complete and precise information about individuals' annual earnings and daily employment histories, presumably without any significant amount of measurement error. ${ }^{11}$ The data are perfectly suited for studying long-run wage profiles because they allow us to construct individual wage profiles for a huge number of labor market entrants over a relatively long period of time. The main drawback of the data is that some important labor market characteristics are not available because they are of no relevance with respect to social security entitlements. First, there is no information about working hours and we therefore can not differentiate between full-time and part-time work. Second, earnings are top-coded because there is a maximum level of regular old-age pension benefits and are therefore only recorded up to the level which yields the maximum benefit. Finally, there is no comprehensive schooling

\footnotetext{
${ }^{11}$ See appendix A for additional details about specific features of the data and about the construction of the key variables.
} 
measure available in the data. We will detail in the next section how we deal with these problems.

The main dependent variable that we use throughout the empirical analysis is the real daily wage in prices of 2007 . That is, the real daily wage corresponds to the real wage per day actually worked. The key regressor is the annual male unemployment rate, which is used as our measure for external labor market conditions at the time individuals first enter into the labor force. We have computed yearly male unemployment rates from the individual-level employment histories contained in the raw data of the ASSD. This procedure has the advantage that we can calculate unemployment rates back until 1972 (compared to published statistics which reach back until 1978 only) and at any desired level of aggregation. We decided to extract yearly male unemployment rates at the state- and the district-level, for both the age group 15 to 65 and the age group 15 to 25 . In general, we use the male unemployment rate for all workers as main regressor, but we also provide some estimates using different rates. ${ }^{12}$

The ASSD also contains a few characteristics at the individual level, like individuals' date of birth, but most of the information relates to individuals' employment spells. For instance, there exists a broad indicator for occupation, distinguishing between blue- and white-collar jobs. Other important characteristics relate to the employer, like the number of employees or industry affiliation. Importantly, the data also contains the geographical location of the employer which allows us to merge the corresponding unemployment rate to each wage-observation at the individual $\times$ year level. On top, as the data allow us to track both individuals and firms over time we can construct additional, time-varying measures like job tenure with the current employer or different indicators of job mobility (across firms, across industries).

\subsection{Sample Selection}

For conceptual reasons, but also due to some important limitations of the data, we do not work with the universe of all labor market entrants but with a specifically selected sample only. First, we restrict our attention to male entrants only. On the one hand, female labor supply behavior over the life cycle is much more difficult to model than male labor supply. On the other hand,

\footnotetext{
${ }^{12}$ It is not obvious whether the youth unemployment rate would be preferable to the overall unemployment rate because the youth unemployment rate may suffer from endogeneity bias. However, as Austria's youth unemployment rate is very low compared to most other countries (e.g. Breen, 2005), the choice between the two is presumably not very important in the end. Nonetheless, we show later on that the choice of which specific unemployment rate to use does indeed not matter a great deal.
} 
we think that we can largely circumvent the problem of missing information about working hours this way simply because most men work full-time. Further, we select workers who enter the labor market sometime between 1978 and 2000, such that we can potentially observe at least five additional years of earnings for each worker (remember that the data run until the end of 2005). As a final restriction, we only focus on workers aged between 15 and 21 at the time they first enter the labor force. Since we proxy schooling by individuals' age at the start of first regular employment, this restriction on age effectively serves as a restriction on individuals' schooling duration (see also appendix A). ${ }^{13}$ Therefore, this restriction essentially excludes individuals with higher education (most importantly individuals with a university degree) but it should include all or most individuals with an apprenticeship training or an education of similar length and scope (like full-time vocational school). ${ }^{14}$ Our final sample thus consists of all male lower-skilled labor market entrants from 1978 until 2000.

Table 1

Table 1 shows descriptive statistics for some key variables, by individuals' age at the time they first enter into the labor force. Throughout, individuals who start their first regular employment after they turn 30 years old are excluded in the first place as they presumably never enter the labor force at all. ${ }^{15}$ The first column of table 1 shows descriptives for all

\footnotetext{
${ }^{13}$ We focus on a sample of labor market entrants such that each entry cohort is balanced with respect to the potential range of schooling. That is, the potential range of schooling (i.e. age at entry) is the same for each year of entry considered in the analysis. In order to determine the start of an individual's first job within the full range of 'education' in each year, we had to restrict the sample period to the years 1978-2000. In the year 1977, for example, we cannot exactly determine the first entry into the labor market for an individual aged 21 because this individual might already have entered the labor market with age 16, i.e. in the year 1971. In this case, his entry is not observed in the data simply because the data do not start before 1972 .

${ }^{14}$ The restriction on schooling is motivated by the following arguments. First, and most importantly, the timing of the first labor market entry (and thus the duration of schooling) may be endogenous. We thus chose to focus on less skilled individuals because we think that they are less likely to manipulate the duration of schooling in order to counteract unfavorable entry conditions. On the other hand, less skilled workers may be more likely to refrain from entering altogether or they may register for unemployment benefits instead of staying in school. This channel is potentially important and we will discuss it in detail in section 4 and in appendix C. Second, unobserved heterogeneity resulting from, for example, unobserved differences in inherent ability is presumably a more urgent problem for higher-skilled workers. Working with a sample of workers with lower education thus helps dealing with unobserved heterogeneity (we will present some tentative empirical evidence in favor of this argument when discussing table 1 below). Relatedly, we believe that promotions - which are not observable in our data - only play a minor role in our sample, at least when compared to highly skilled workers for whom promotions are important as regards long-run wage profiles (Baker et al., 1994b; Gibbons and Waldman, 1999). Moreover, because the ASSD contains no comprehensive schooling measure we have to use age at first entry into the labor force as proxy for schooling and we think that this proxy probably works well only for less-educated workers. Finally, including only less-skilled workers in the sample is a very effective way of minimizing the practical problem that wages are right-censored.

${ }^{15}$ If we think about individuals who enter at a later age, this group of workers most likely consists of two very different groups, but they are indistinguishable from each other in the data. On the one hand, there are
} 
individuals, the second (third) column shows descriptives for individuals aged 15 to 21 (aged 22 to 30 ) when first entering the labor market. The comparison of the second to the third column shows that our sample restriction with respect to our schooling proxy (i.e. age at first entry) works as expected. The sample of lower skilled workers, compared to the group of higher skilled workers, contains a higher fraction of blue-collar workers, has considerably lower wages on average and shorter duration of the first regular employment spell.

Note that, in the group of individuals aged between 22 and 30 when first entering the labor force, highly skilled workers potentially are mixed up with low-skilled workers: individuals in this group of workers either they spent much time in education or were unemployed before (or had short employment spells not counting as regular employment). This is evident from the proportion of workers below the lower censoring point or above the higher censoring point. The probability of crossing any of the two points is higher for the sample of older workers. Consequently, the variation in the real daily wage (and thus productivity) is considerably smaller in the sample of younger workers than in the group of older workers, regardless of the exact wage measure we look at. For example, the standard deviation of the log real daily wage is much higher in the group of younger workers than in the group of older workers. As regards the location of a worker's first employment we see that there is more variation with respect to both of those variables in our sample than in the overall sample or the sample of older workers. On the other hand, however, younger workers seem to be more clustered with respect to the industry of their first employment spell than older workers.

\subsection{Sample Description}

Because we follow all individuals from the year of their first regular employment onwards until the end of the data in the year 2005, the resulting data set would have been huge. In the following we thus work with a $30 \%$ random sample of all labor market entrants aged between 15 and 21. Table 2 presents descriptive statistics for this sample of labor market entrants that we actually use in the empirical analysis (note that the first column should therefore reproduce the corresponding numbers from table 1, apart from sampling variation). Our final sample

truly high-skilled workers who enter the labor market at a later stage because they have stayed in school until that time. On the other hand, however, there are also low-skilled workers who have not been employed or only sporadically employed before starting their first regular employment. Because schooling is not directly observed, we will necessarily mix these two groups of workers together. 
contains about 224,000 individuals and about 3.5 million wage observations (i.e. observations at the level of individual $\times$ year).

\section{Table 2}

Table 2 shows that the average labor market entrant in our sample is about 19 years old and holds his first job for almost three years. The average age at the start of one's first job fits the fact that mandatory schooling ends in the year when individuals turn age 16 and that apprenticeships normally last for two to four additional years. The high fraction of bluecollar occupations is consistent with our intention to only include individuals involved in some kind of vocational training. Interestingly, a significant fraction of the sample (about a third) experiences some unemployment before finding the first job. On average these individuals are registered for unemployment benefits for somewhat more than one month. In consistence to this observation we find age at first entry to be about half a year lower than age at the start of the first regular job, reflecting the fact that the transition from education to work often involves short periods of nonemployment. The average real starting wage amounts to about $47 €$ per day worked. Note that there is no real censoring problem as only very few individuals earn starting wages either around the lower or around the upper censoring point thanks to our sample selection rules.

The next panel of table 2 shows the male unemployment rate at two different levels of aggregation as well as the yearly aggregate number of labor market entrants. Both unemployment rates refer to the male working-age population (i.e. aged between 16 and 65) and have been computed from the individual-level data of the ASSD. The average unemployment rate in the year of labor market entry is about $6.5 \%$ and there are about 3,700 male individuals entering the labor market in any given state and year. ${ }^{16}$

As regards employer-related characteristics, the lower panel of table 2 shows that our sample predominantly consists of individuals working in either manufacturing, construction, or in wholesale and retail trade. There are also significant shares of workers in gastronomy and hotel business, transportation, finance as well as lobbies and social security agencies. Again, this matches our purpose to only include lower skilled individuals. The high number of average

\footnotetext{
${ }^{16}$ In the analysis, we check whether our results still hold when using published unemployment data or using the youth unemployment rate. It turns out that our results are very robust to the choice of unemployment rate actually used in the analysis.
} 
employees per entry firm (about 600) hides the fact that most firms are small and thus that most individuals are actually working in small firms. In fact, about $40 \%$ of all entrants start their first regular employment in a firm with 25 or less employees. Also, the firms in our sample predominantly engage males, presumably reflecting the gender distribution across industries. We also see that workers rarely start their career in seasonal firms as it is evident from the number of quarters a specific employer is observable in the data per year (i.e. this variable counts the number of quarterly reference dates on which firm has at least one employee).

\section{The Persistence of Initial Labor Market Shocks}

Panel (a) of figure 1 shows long-run wage profiles for all labor market cohorts who have first entered into the labor force sometime between 1978 and 2000. The black dots represent average starting wages for each entry cohort and thus the dashed grey line shows how starting wages evolve over time. Clearly, real starting wages have increased significantly over the period of analysis, from about $37 €$ in 1978 to about $50 €$ in 2000 . Also note that there is some cyclical movement in starting wages over time which we expect to be related to economic conditions prevailing in that year. ${ }^{17}$ The filled colored lines on the other hand represent long-run wage profiles of cohorts entering the labor market in different years. Clearly, cohorts' wages follow an approximate concave path over time, implying that wage growth is highest in earlier working years and then strongly flattens later on. Panel (a) for example shows that the 1978 entry cohort starts with a real starting wage of about $41 €$ per workday and experiences a raise in real wage to about $97 €$ until the year 2005. On average, this cohort's real compensation has therefore more than doubled in the first 27 years of labor market experience.

Figure 1

Panel (b) is a rescaled version of panel (a), making the differences in wage profiles across entry cohorts more evident. It shows cohorts' approximate wage growth (relative to their starting wage) over the number of years of potential labor market experience. It thereby makes the concavity of cohorts' wage profiles even more obvious than panel (a). Looking at the 1978 entry cohort again, panel (b) shows that this cohort's average wage has grown by

\footnotetext{
${ }^{17}$ Indeed, appendix B shows that part of the cyclical pattern of starting wages relates to corresponding variation in the unemployment rate and that starting wages are lower when unemployment is high.
} 
approximately $145 \%(=[\exp (.9)-1] \cdot 100 \%)$ in the first 27 years of experience. Evidently, most of this wage increase happens at the early stage of the labor market career (i.e. the wage increase in the first ten years equals $86 \%(=[\exp (.62)-1] \cdot 100 \%))$. On top, long-run wage profiles of different entry cohorts have quite some distinct overall shapes. More specifically, the figure shows that returns to experience have in general decreased over time, meaning that younger entry cohorts have considerably lower returns to labor market experience than older cohorts. The 1995 cohort for example has only realized an average wage increase of about $58 \%$ $(=[\exp (.46)-1] \cdot 100 \%)$ in the first ten years, which is much smaller than the corresponding increase of the 1978 entry cohort.

In comparison, figure 2 shows the evolution of local unemployment rates which we use as indicator for external labor market conditions at the time individuals first enter into the labor force. More specifically, the dotted red lines in figure 2 show annual male unemployment rates at the level of the state and the dashed blue lines show annual male unemployment rates at the level of the district (both are computed from the raw data of the ASSD).

Figure 2

Figure 2 makes another point apparent that is important for the empirical analysis: the years 1978-2000 cover several periods of both boom and downturn, and the identifying variation in initial labor market conditions therefore stems not from a few neighboring labor market cohorts only. A comparison across states makes it also clear that the states not only differ in the level of unemployment but also with respect to cyclical variations around a longer run trend: although all states have seen an increase over the whole observation period in general, there are marked cyclical differences across states and districts. For example, Burgenland has experienced a huge increase in the unemployment rate from about $3 \%$ in the 70 s to about $7-8 \%$ in the first half of the eighties and then to about $9 \%$ in the second half of the eighties. Vorarlberg, in contrast, experienced only a modest increase in the 80s, from a very low level of about $1 \%$ to about $3 \%$. However, there was sharp increase at around 1992, when unemployment went up from about $3 \%$ to $7-8 \%$. 


\subsection{Econometric Model}

In the econometric analysis, we will pay particular attention to modeling the concavity of long-run wage profiles which is evident from figure 1. Second, we want cohorts' wage profiles to be a function of the initial unemployment rate. This means that we allow potential effects to become weaker or stronger as labor market experience increases. Our basic econometric model looks as follows:

$$
\ln \left(y_{i t}\right)=\ln \left(u r_{j[i]}^{0}\right) \alpha_{1}+\kappa\left(\exp _{i t}\right) \alpha_{2}+\left[\ln \left(u r_{j[i]}^{0}\right) \cdot \kappa\left(\exp _{i t}\right)\right] \alpha_{3}+x_{i} \beta+\psi_{j}+t_{i} \gamma_{j}+\epsilon_{i t}
$$

where $y_{i t}$ denotes the real daily wage of individual $i$ in year $t$, $\exp _{i t}$ is potential labor market experience of $i$ in year $t$, and $u r_{j i i]}^{0}$ is the unemployment rate that was prevailing in region $j$ at the time individual $i$ first entered into the labor market. Function $\kappa(\cdot)$ denotes that we allow for a flexible functional form with respect to labor market experience. ${ }^{18}$ The effect of the initial unemployment rate on current wages is allowed to change as labor market experience increases by means of interaction terms between the experience polynomials and the initial unemployment rate. We further include several control variables, subsumed by vector $x_{i}$, all of which are predetermined in the sense that they relate to an individual's first regular employment spell or to the time before having started to work. Specifically, we include our proxy for schooling (i.e. age at first entry), the log of the absolute number of labor market entrants in the year and state of first entry, an indicator for blue- and white-collar occupation each, the number of employees and the fraction of the workforce that is female, as well as location and industry of the first employer. Finally, we include a set of state dummies $\left(\psi_{j}\right)$ and state-specific quadratic time trends $\left(t_{i} \gamma_{j}\right)$. Of main interest are parameters $\alpha_{1}$ to $\alpha_{3}$ which together describe the wage-experience profile as a function of the initial unemployment rate. Specifically, $\alpha_{1}$ is the elasticity of wages with respect to the initial unemployment rate in the year of first entry (i.e. in the year where labor market experience is equal to 0), while $\alpha_{2}$ and $\alpha_{3}$ tell us how the effect of initial conditions changes as labor market experience increases.

Some additional remarks about the econometric model which is given by equation (1) are in

\footnotetext{
${ }^{18}$ Specifically, we include the first three polynomial terms of potential labor market experience. We have chosen the number of polynomial terms on the basis of a non-parametric, and therefore fully flexible wageexperience model. The first three polynomial terms appear sufficient to reproduce the wage-experience profile predicted from the corresponding non-parametric model.
} 
order. First, we intentionally do not control for any time-varying variables like tenure because we view those characteristics as potentially influenced by initial economic conditions. ${ }^{19}$ Therefore, parameters estimates of equation (1) correspond to the overall effect of initial conditions and this overall effect may be the result of several different mechanisms at work. We will study some specific adjustment mechanisms later in section 4. Second, because the regressor of key interest (i.e. the initial unemployment rate) does not vary over time for any given individual we can not use standard panel data methods like fixed-effects or first differences as these methods wipe away not only all unobserved time-invariant heterogeneity but also all variation in the key regressor. For this reason, we rely on estimation by simple pooled OLS. Third, the model given by equation (1) is in general not identified non-parametrically because it includes cohort, experience as well as year effects (Rodgers, 1982). Therefore, although not immediately evident, our model is identified only by imposing some assumptions with respect to the functional form of the regression model. ${ }^{20}$ Finally, we have to take into account that our key regressor is observed at a higher level of aggregation than the dependent variable, a fact that may lead to grossly misleading inference (Moulton, 1986), and serial correlation in the error term is an additional issue (Bertrand et al., 2004). We tackle both of these problems simultaneously by applying the multiway-clustering method proposed by Cameron et al. (2006) which allows for clustering at the level of year and state at the same time. ${ }^{21}$

\subsection{Main Results}

Our main results are shown in table 3 and graphically displayed in figure 3 . The top panel of table 3 shows point estimates of the key parameters, while the middle panel shows the elasticity of real daily wages with respect to the initial unemployment rate at different specific values of labor market experience. Because quite many parameters are involved, it's somewhat easier

\footnotetext{
${ }^{19}$ The only exception is that we implicitly condition on current state of work because we include state dummies as well as state-specific trends.

${ }^{20}$ Our model needs even more restrictions because we are interested in the effect of a time-invariant regressor, which makes the problem of collinearity even worse. First, we estimate a parametric experience-wage profile in most models, although the additional restrictions that we impose would allow us the estimate the profile in a non-parametric way. There is a second parametric restriction with respect to age at first entry, our proxy for schooling, as we don't allow the returns to schooling to change across cohorts. Finally, we also impose parametric restrictions on the time trend of wages.

${ }^{21}$ However, we believe that these standard errors provide a lower bound on statistical precision. As noted by Wooldridge (2003), such an adjustment to standard errors may be overly conservative if there are many individual-level observations but only a few clusters, as in our sample.
} 
to illustrate the substantive implications of the estimates graphically. Figure 3 therefore plots the estimated elasticity of real wages with respect to the initial unemployment rate, along with its $95 \%$ confidence interval, against potential years of labor market experience.

Table 3 and Figure 3

The model in the first column only includes the logarithm of the number of labor market entrants, a set of state dummies and a common time trend as control variables. As expected, there is an immediate negative effect in the year of entry. As shown by the point estimate in the first row, the wage elasticity with respect to the initial unemployment rate equals -0.026 in the year of entry, i.e. in the year when labor market experience is zero. However, this initial negative effect fades away quite quickly as labor market experience increases. This is evident from the middle panel of table 3 or, more clearly, from panel (a) of figure 3 .

In the second column, we include state-specific quadratic time trends instead of imposing a common trend across regions. This is based on the empirical observation that the states differ quite strongly with respect to overall economic conditions (see figure 2 again). The resulting initial negative effect appears to be quite a bit larger in this case, however without changing the overall pattern by much. The estimated elasticity in the entry year is now -0.045 , or about $70 \%$ larger than the corresponding estimate of the first model.

The estimates shown in the third column are also based on a model with state-specific time trends, but which additionally includes control variables at the individual-leve. (most of them relate to the first regular employment spell or even the time before). Adding these individual-level controls makes the short-run effect of the initial unemployment rate larger again. The point estimate of the initial elasticity is now -0.062 and now even reaches statistical significance, the very conservative adjustment to standard errors notwithstanding. ${ }^{22}$ Further, the pattern of estimated elasticities over labor market experience has markedly changed. In particular, panel (c) of figure 3 shows that all estimated wage elasticities with respect to the initial unemployment rate turn out to be negative, even twenty years after labor market entry.

Column (4) additionally allows for cohort-specific returns to experience by adding interaction terms between the polynomials of labor market experience and the entry year. This

\footnotetext{
${ }^{22}$ The impact on estimated standard errors of taking the grouping-level nature of the initial unemployment rate into account is huge. For example, clustering standard errors on the individual level instead of clustering on state and year yields a standard error of the coefficient on the log initial unemployment rate of about 0.003 , or about a ninth of the standard error shown in table 3 .
} 
accounts for the steady downward shift in returns to experience as evident in panel (b) of figure $1 .^{23}$ Allowing for varying returns to experience makes the short-run effect again larger (point estimate of the initial elasticity is now -0.075) but the long-run effect somewhat less persistent (see panel (d) of figure 3). The change in the shape of the wage elasticities at the higher values of experience presumably reflects the imbalance of our sample as regards potential labor market experience - older cohort are observed for longer periods than younger cohorts. It is thus empirically difficult to allow for varying slopes of the wage-experience profile while estimating cohort-specific long-run wage profiles at the same time. We therefore choose the model in column three to be our baseline model. We will take this issue up again in section 3.3 however.

As to further illustrate the substantive economic implications of our estimates, panel (a) of figure 4 shows predicted wage profiles for three hypothetical labor-market entry cohorts, all endowed with average observable characteristics but entering the labor market at different initial unemployment rates. More specifically, we predict the wage profile for a cohort entering the labor market either at a very low, at the average, or at a very high value of the initial unemployment rate. Predictions are based on parameter estimates shown in column three of table 3. We view the 90th percentile (which corresponds to an unemployment rate of about $10.4 \%$ ) of the observed distribution of the initial unemployment rate as a value representing a high level of unemployment. Similarly, we view the 10th percentile (about 2.3\%) as representative for a low level of unemployment. The predicted wage profile of the cohort entering in a year of average unemployment (equal to about $6.5 \%$ ) shows the typical concave pattern of cohorts' wage-experience profiles (compare with figure 1). The profiles of the two cohorts entering in either times of very low or very high unemployment show quite different patterns. Clearly, the difference in wage profiles is largest in the very first year of labor market experience. But even though the difference gets smaller as labor market experience increases, it does not completely vanish - even after twenty years of experience.

\section{Figure 4}

The bottom panel of figure 4 makes the differences across the hypothetical cohorts more visible by showing their deviation from the cohort that faced average entry conditions. The immediate wage loss resulting from entering the labor market in a recession as opposed to

\footnotetext{
${ }^{23}$ Note that we can only estimate the interaction terms, but not the main effect of the year of entry because it is perfectly collinear with calendar year and age at first entry.
} 
entering in times of average conditions (in a boom) amounts to about $4 \%$ (10\%). This initial loss gets smaller as experience increases, and after about five years the loss from facing bad entry conditions has gone down to a remaining annual wage penalty of about $1 \%$.

Although initial differences in wages clearly fade away as labor market experience increases, and even though differences in later years appear to be very small, our main estimates imply large negative effects of entering in an economic downturn on lifetime earnings, as opposed to entering in average or good times. This is illustrated in figure 5 which shows the present discounted value of accumulated losses (gains) in lifetime earnings, using a real discount rate of either $0 \%$ or $8 \% .{ }^{24}$

\section{Figure 5}

Because there is still a difference in wages between the three hypothetical cohorts at higher levels of labor market experience, the choice of discounting does actually make quite a difference as regards the present value of the loss in lifetime earnings. Even if we use a constant real discount rate of $8 \%$ per year, there still results a substantial loss in the present discounted value of lifetime earnings on the order of about $15 \%$, if one compares the long-run wages profile of workers entering during bad versus average conditions.

Even if we compare less extreme values of initial labor market conditions, there still result sizable effects on the present value of lifetime earnings. For example, we may compare a cohort that is entering into the labor force when unemployment is about $20 \%$ higher than for the cohort entering in times of average unemployment. Our estimates imply that those workers from a cohort entering in times of higher unemployment would still incur a loss in lifetime earnings of about $5 \%$ after twenty years of labor market experience ${ }^{25}$

\footnotetext{
${ }^{24}$ The main reason why we want to discount earnings losses at higher values of labor market experience relates to the fact that we can estimate early wage differentials more precisely in the sense that the estimates of early losses are estimated using a much broader range of entry (and thus birth) cohorts than the losses in later years.

${ }^{25}$ The average unemployment rate at entry is about $6.5 \%$, and so the 90th percentile of the initial unemployment rate $(10.4 \%)$ is about $60 \%$ higher than the average. These are the numbers used for the calculations shown in figure 5. Instead, using an unemployment rate which is only about $20 \%$ higher than the average (for example by increasing the average initial unemployment rate from $6.5 \%$ to $7.8 \%$ ) would thus still result in a loss of lifetime earnings equal to about a third of the effect shown in figure 5.
} 


\subsection{Sensitivity Analysis}

Table 4 shows some alternative estimates, all of them based on simple modifications of our baseline model. ${ }^{26}$ A first robustness check relates to the concern that the estimated impact may be driven by heterogeneous effects across (groups of) individuals. As a first check, we therefore exclude individuals with lowest and highest starting wages. As the first two columns of table 4 show, the key estimates hardly change across samples (in statistical terms). Even though the initial impact is somewhat smaller in both cases, the long-run pattern of the effect remains very much the same as in the baseline model based on the full sample (see column 3 of table 3). As a second check, we exclude workers who could not have been unambiguously classified as workers starting their career as either a blue- or a white-collar worker (see column 3). Again, although slightly different point estimates result, both the immediate effect of initial conditions and the overall pattern of wage elasticities is essentially the same as in the baseline model.

Table 4

The remaining three columns of table 4 show estimates based on alternative unemployment rates. We use the male unemployment rate taken from published statistics in the model shown in column 4 (Bundeskammer für Arbeiter und Angestellte, 1980-2003). The model in column 5 uses the youth unemployment rate, which we have also computed from the raw data of the ASSD and which relates to male workers aged between 15 and 25. Finally, we use the unemployment rate at the district-level in the last model in table 4 . In this case, the crosssectional dimension with respect to variation in the unemployment rate is markedly increased as there are 35 districts, compared to only nine states in the case of the other unemployment rates. On the one hand, this should bring down standard errors as the clustering is now done on 35 instead of nine observations in the cross-sectional dimension. On the other hand, using the unemployment rate at a more disaggregated level may run the risk of being endogenous as workers may move to regions with lower unemployment (Wozniak, 2006). However, it turns out

\footnotetext{
${ }^{26}$ We use the $\log$ of the initial unemployment rate as our main regressor throughout the analysis. We made this choice of model specification partly because it is the standard specification in the wage-curve literature (e.g. Blanchflower and Oswald, 1990). On the other hand, our own analysis of the association between initial labor market conditions and starting wages (see appendix B for details) has led us to think that this model is an appropriate and parsimonious choice. Nonetheless, we have also re-estimated our main results using the level of the initial unemployment rate as regressor. This yields similar results, even though the cyclical movement appears to be more pronounced in this case (results not shown).
} 
that the choice among different unemployment rates does not play a critical role. Using either the overall male unemployment rate taken from published data or the youth unemployment rate computed from the ASSD yields estimates very similar to the baseline results, both in the shortand the long-run. There is, however, a notable difference between using the unemployment rate at different levels of regional aggregation: using the unemployment rate at the district level results in a more persistent effect overall, as shown by the pattern of elasticities shown in the last column of table 4 . This may hint at the potential endogeneity of the unemployment rate at lower aggregation levels, resulting from workers moving to regions with initially lower levels of unemployment in order to increase the probability of finding a job.

\section{Table 5}

One issue that may be of more concern is the mechanical imbalance in our data, an imbalance which results from the fact that older cohorts are observable for a longer period of time than younger cohorts in our sample. As a result, our data are imbalanced with respect to potential labor market experience by construction. We therefore re-estimate our main model on different sub-samples which are all balanced with respect to potential labor market experience. For example, the first column of table 5 includes all entry cohorts, but it excludes all observations with potential labor market experience larger than five years such that the maximum observed experience is the same for all cohorts. Thus, this sample contains the maximum range of entry cohorts, but it does not really allow estimating long-run effects as only the first five years of experience are considered. In the last column, on the other hand, we only include the older entry cohorts for whom we can observe a large number of calender years. Overall, table 5 shows that the pattern of wage elasticities with respect to the initial unemployment rate is largely unaffected by correcting the sample for its imbalance in labor market experience, albeit the point estimates differ somewhat. In all four cases, there is a negative and statistically significant effect in the year of entry which then fades away as labor market experience increases. Our results therefore do not to hinge on the imbalance with respect to labor market experience and they are not driven by a few specific entry cohorts only. 


\section{Adjustment Mechanisms}

As we have detailed in the introduction, different mechanisms may be able to explain the persistence of initial labor market shocks and the sluggish adjustment of wages that we have documented so far. In this section, we provide empirical evidence on three main mechanisms in some detail.

First, endogenous (timing of) labor market entry over the business cycle may result in compositional changes of entry cohorts. Thus, what appears to be an effect driven by initial economic conditions might in fact only reflect differences in the composition of labor market cohorts. However, we expect that sample selection - if present at all - will tend to make our estimates smaller than they actually are because it seems reasonable to assume that only the highly qualified job candidates get a position in times of high unemployment. Those who miss out are likely to be the least educated. In such a situation, our estimates will likely correspond to a lower bound of the true effect.

Second, as discussed in the introduction, features of internal labor markets (e.g. formal salary systems, long-term wage contracts) may also play a role not only with respect to the immediate effect of labor market conditions, but also with respect to the long-run adjustment of wages. To this end, we study the mediating role of an individual's initial occupational status on the impact of initial conditions on wages.

Third, not only may it be more difficult to find a job in times of high unemployment, workers who actually start their employment career in a recession may it also find more difficult to switch to another job in the first few years until economy recovers. This implies that workers starting their career in a recession are more likely to exhibit a lower mobility in the early working years or even get stuck in their first job with a higher probability than workers starting in a boom. As job mobility in early years of a labor market career is often associated with real increases in wages, workers entering in a recession probably miss some important opportunities. On the other hand, job retention, i.e. staying with the first employer instead of switching between jobs, may also have a positive effect on wages through the accumulation of firm-specific human capital. Further, sluggish adjustment at the macroeconomic level (as evident from figure 2) may itself also be an important factor behind the long-run adjustment of wages, as wages may arguably only adjust once macroeconomic conditions have improved. For 
example, it may be the case that the job-mobility prospects of workers entering in a recession only become more fortunate once the economy as a whole has recovered.

\subsection{Endogenous Labor Market Entry}

The timing of labor force entry and thus the composition of labor market cohorts may be endogenous for several distinct reasons. First, some potential labor market entrants, when faced with an exceptionally high unemployment rate, may refrain from entering the labor market altogether. We think that this effect is rather unlikely to be of significant importance on our case because we focus on less educated men only. Second, both the choice of education as well as the duration of schooling may be endogenous as both job prospects are weak and opportunity costs of schooling low in times of high unemployment. Again, we think that in our specific sample the choice of education is probably of less relevance, albeit some individuals may try to receive some further training when facing bad job opportunities. ${ }^{27}$ The most likely reason for endogenous labor market entry is that some workers will simply delay their entry when faced with unfavorable entry conditions, either by registering for unemployment benefits or by staying out of the labor force until they find a job. In any case, if those workers who don't get a job immediately are a selected group of all workers who intend to enter employment in a given year, then the composition of the actual entrants changes along with corresponding changes in the unemployment rate and thus potentially biases the estimated effect of the initial unemployment rate on wages. ${ }^{28}$

One straightforward and easy way to take sample selection over the business cycle into account is to consider the time from the first possible year of entry until the actual entry as part of the outcome. We therefore re-estimate our baseline model, using the local unemployment

\footnotetext{
${ }^{27}$ A significant part of initial vocational training in Austria is provided by dual apprenticeship training schemes, i.e. practical training provided by firms while attending part-time compulsory vocational school. Apprenticeships last from two to four years, depending on occupation. Full-time vocational and technical schools provide an important alternative to apprenticeship training, and they also last up to four years. Details are given in the report by the Federal Ministry for Education, the Arts and Culture (2008).

${ }^{28}$ However, we can not say much about the first effect because we observe individuals only after they have actually started to work. Individuals who refrain from entering the labor force altogether are not covered by the data at all. However, we can study delayed entry into the labor force as a consequence of bad labor market conditions (see appendix C). Indeed, the data suggest that there are considerable short-run effects of the initial unemployment rate on labor force participation, whereas a significant part of the effect appears to run through registering for unemployment benefits. Most importantly, as expected we find evidence for positive sample selection in times of high unemployment (again, see appendix C). This finding is in line with previous studies (e.g. Kahn, 2009; Oreopoulos et al., 2008).
} 
rate at age 16 (compulsory schooling ends in the year individuals turn age 16) instead of the local unemployment rate in the year of actual labor market entry:

$$
\ln \left(y_{i t}\right)=\ln \left(u r_{j[i]}^{16}\right) \alpha_{1}+\kappa\left(\exp _{i t}\right) \alpha_{2}+\left[\ln \left(u r_{j[i]}^{16}\right) \cdot \kappa\left(\exp _{i t}\right)\right] \alpha_{3}+x_{i} \beta+\psi_{j}+t_{i} \gamma_{j}+\epsilon_{i t}
$$

with $u r_{j[i]}^{16}$ denoting the unemployment rate in region $j$ in the year in which individual $i$ turned 16 years old. Figure 6 illustrates the substantive results from estimating the model given by equation 2: panel (a) shows the predicted wage profiles for the same three hypothetical entry cohorts as discussed in section 3.2 before, panel (b) shows the predicted profiles minus the profile of the cohort entering at average initial unemployment, and panel (c) shows the estimated present discounted value of accumulated losses (gains) in earnings (the corresponding parameter estimates are given in the column 2 of table 6 ).

Figure 6 and Table 6

A comparison of figure 6 with figure 4 (our baseline estimates) clearly shows that taking sample selection into account not only results in a larger immediate effect but also makes it more persistent. This result is consistent not only with our prior expectations, but also with the empirical results summarized in appendix C. Specifically, the immediate effect when using the unemployment rate at age 16 is -0.094 , about $50 \%$ larger than the baseline estimate of 0.062 (compare columns 1 and 2 of table 6 ). The increase in the estimated elasticities at higher values of experience are even larger. For example, the elasticity at ten years of labor market experience is -0.011 in the baseline model but is about twice as large when taking selection into account (the resulting point estimate is -0.023). This results in quite a large difference as regards the impact of initial labor market conditions on the present discounted value of lifetime earnings. While the baseline model predicts a loss in lifetime earnings for entering the labor force during a recession (in comparison to entry at average conditions) of about $15 \%$ after twenty years of labor market experience, the point estimates that take sample selection into account imply a loss of more than $30 \%$ after twenty years of experience.

\subsection{Initial Occupational Status}

The distinction between blue- and white-collar workers is informative because several constituents of internal labor markets like initial job placement and job promotions, implicit wage 
contracts, but also formal salary systems are arguably more important for white-collar than for blue-collar workers. From the perspective of internal labor markets, we expect initial job placement, job promotions and formal salary systems to be more important for white-collar than for blue-collar workers. Indeed, Schwerdt et al. (2009) show that Austrian white-collar workers suffer from much more persistent wage losses resulting from job displacement than blue-collar workers, although both groups suffer from quite substantial initial wage losses. We therefore re-estimate our baseline model for blue- and white-collar workers separately. ${ }^{29}$ Resulting parameter estimates are shown in columns 4 and 5 of table 6 , separately for blue- and white collar workers. Figure 9 again illustrates the quantitative implications graphically.

\section{Figure 9}

First note that, even though average starting wages are quite similar between blue- and white-collar jobs, wage profiles are much steeper and thus wage growth is much higher for white-collar workers (at least initially). This is presumably reflecting the fact that seniority payments, probably as an incentive scheme as argued in Lazear (1979) or Lazear and Rosen (1981) for example, or formal salary systems in general, are more important in white-collar than in blue-collar occupations.

Interestingly, figure 9 shows that white-collar workers suffer from much larger immediate losses than blue-collar workers. This result is in line with Schwerdt et al. (2009) who also find the short-run effects of displacement to be much larger for white-collar than for blue-collar workers. As a consequence, the losses are much more persistent in the longer run (although the speed of wage adjustment is higher for white-collar workers). The resulting loss in lifetime earnings therefore is estimated to be quite small for these workers and equals about $5 \%$ if evaluated at twenty years of labor market experience. The corresponding figure for whitecollar workers is much higher and equals about 31\%, about six times as large as the earnings loss for blue-collar workers.

\footnotetext{
${ }^{29}$ Because blue- and white-collar workers in Austria are partially subject to different social security rules and because they are covered by different social security agencies, we can easily determine workers' occupational status, without any significant measurement error. Again, note that some (few) workers could not have been classified as neither blue- nor as white-collar workers. These workers are left out in the following analysis, and therefore the sample sizes do not exactly add to the total sample size used in the baseline model.
} 


\subsection{Job Mobility, Accumulation of Human Capital, and the Business Cycle}

Entering the labor market when unemployment is high may not only make it more difficult to find a job in the first place, it may also affect individuals' mobility prospects and the accumulation of human capital in the years immediately following labor market entry. We first show that initial economic conditions influence variables describing mobility and human capital accumulation before estimating their impact on long-run wage profiles. Because both cohorts' mobility and employment patterns show strong non-monotonic behavior over the course of experience, we estimate non-parametric versions of our baseline model:

$$
\omega_{i t}=\sum_{k=0}^{27} 1\left(\exp _{i t}=k\right) \alpha_{1 k}+\sum_{j=0}^{27}\left[1\left(\exp _{i t} \cdot \ln \left(u r_{j[i]}^{0}\right)\right] \alpha_{2 k}+x_{i} \beta+\psi_{j}+t_{i} \gamma_{j}+\epsilon_{i t}\right.
$$

where $\omega_{i t}$ denotes the outcome variable of interest for individual $i$ observed in year $t$ and $k=0, \ldots, 27$ indexes the potential number of years of labor market experience. Specifically, we analyze six different outcome variables. The first three outcomes are indicator functions for mobility across jobs and across industries as well as an indicator for - either temporary or permanent - movement from employment to inactivity. The remaining outcome variables are the annual number of days worked, the annual number or days spent in registered unemployment and job-tenure with the current employer. As before, we allow the effects of initial conditions to vary with experience by including interaction terms of the initial unemployment rate and experience.

\section{Figure 7}

Figure 7 gives a succinct summary of the results by plotting the estimated elasticities of each outcome with respect to the initial unemployment rate (i.e. $\left.\hat{\alpha}_{2 k}\right)$ against potential labor market experience (denoted by $k$ ). Panels (a) and (b) of figure 7 show the estimated elasticities of the probability of changing jobs or changing industries with respect to the initial unemployment rate. These two figures not only show that bad entry conditions reduce mobility in the year of labor market entry, but also that they permanently change individuals' long-run mobility patterns. Panel (c) shows that there is no (or a small negative) effect on the probability of (temporarily or permanently) leaving the labor force. Note that this effect is consistent with positive sample selection in times of high unemployment. Not surprisingly, panel (d) shows a 
positive effect of initial labor market conditions on the annual number of unemployment days in the first few years of potential labor market experience. However, there are no long-run effects of initial conditions on average unemployment duration: the point estimates after about five years of experience are essentially zero. More interestingly, panel (e) reveals a positive effect of a high initial unemployment rate on the annual number of workdays. This does not hold in the year of entry, but it holds in the following four to five years. This effect appears somewhat surprising at first sight, but we think that it can easily be rationalized as being the mirror image of the negative effect on mobility in the first few years of experience. Consequently, we also find a positive effect of the initial unemployment rate on job tenure with the current employer for almost the whole range of potential labor market experience, as is evident from panel (f) of figure 7 .

It thus appears that two closely related but countervailing effects are at work (indeed, the two effects are two sides of the same coin). On the one hand, unfavorable entry conditions reduce job mobility while, at the same time, they increase employment duration and therefore job tenure with the current employer. While both job mobility and accumulation of human capital through job retention have positive effects on wages per se, the overall effect appears to be ambiguous. To determine the sign and the size of the overall effect of changes in mobility, employment and tenure, we estimate a simple variant of our baseline model:

$$
\begin{aligned}
\ln \left(y_{i t}\right)= & \ln \left(u r_{j[i]}^{0}\right) \alpha_{1}+\kappa\left(\exp _{i t}\right) \alpha_{2}+\left[\ln \left(u r_{j[i]}^{0}\right) \cdot \kappa\left(\exp _{i t}\right)\right] \alpha_{3}+\operatorname{ten}_{i t} \delta_{1}+\left[\operatorname{ten}_{i t} \cdot \kappa\left(\exp _{i t}\right)\right] \delta_{2} \\
& +\operatorname{empl}_{i t} \delta_{3}+\Delta \operatorname{job}_{i t} \delta_{4}+x_{i} \beta+\psi_{j}+t_{i} \gamma_{j}+\epsilon_{i t},
\end{aligned}
$$

with ten ${ }_{i t}$ denoting job tenure with the current employer (in years), empl ${ }_{i t}$ denoting the annual number of days worked, and $\Delta \mathrm{job}_{i t}$ being an indicator variable taking on the value 1 if an individual has changed jobs between year $t-1$ and $t$ and 0 otherwise. We also allow the effect of tenure to vary with labor market experience by including the corresponding interaction terms because early job-tenure may have larger effects on wages than tenure accumulated later on. Note that this model is essentially the same as the baseline model discussed before (see column 3 of table 3), except that we additionally include some time-varying regressors which we have so far considered as potential outcomes (and therefore not included as regressors). Results are shown in figure 8 as well as in column 3 of table 6 . 
Figure 8

Interestingly, it turns out that conditioning simultaneously on the future paths of mobility, employment and tenure makes the negative impact of the initial unemployment rate slightly more persistent than in the baseline model, without much impact on the immediate effect in the year of first entry. Therefore, even though individuals' mobility chances are decreased at least in the first few years after entry, this appears to be (more than) offset by the countervailing positive effect on employment days and on job tenure. In other words, if there were no adjustments with respect to job mobility, employment and tenure across the different entry cohorts, then the negative effect of entering in bad conditions would be slightly larger than what we actually observe to happen. If we hold adjustments though changes in mobility and employment constant, we estimate a present discounted value of earnings loss after twenty years of experience of about $19 \%$, compared to about $15 \%$ in our baseline model. Thus adjustments through changes in mobility and employment have a significant, albeit quite small, dampening effect as regards the impact of initial conditions on wages in the longer run.

A final point that we want to make relates to the role played by aggregate labor market conditions. Indeed, the persistence in aggregate labor market conditions, which is evident from figure 2 for example, suggests that it may also be important to study the role of the business cycle itself as part of how wages adjust to initial labor market shocks. Individuals who enter into the labor force in times of high unemployment will presumably face more favorable economic conditions some years after their entry, whereas on the other side the initially lucky are more likely to be confronted with unpleasant conditions sometime later in their labor market career. As to study the potential impact of the business cycle itself as driving factor behind long-run wage adjustment, we add the current unemployment rate as an additional regressor to our baseline model. Formally, we estimate the following regression model: ${ }^{30}$

$$
\begin{aligned}
\ln \left(y_{i t}\right)= & \ln \left(u r_{j[i]}^{0}\right) \alpha_{1}+\kappa\left(\exp _{i t}\right) \alpha_{2}+\left[\ln \left(u r_{j[i]}^{0}\right) \cdot \kappa\left(\exp _{i t}\right)\right] \alpha_{3}+x_{i} \beta+\psi_{j}+t_{i} \gamma_{j} \\
& +\Delta \ln \left(u r_{j t}\right) \delta_{1}+\left[\Delta \ln \left(u r_{j t}\right) \cdot \kappa\left(\exp _{i t}\right)\right] \delta_{2}+\epsilon_{i t}
\end{aligned}
$$

\footnotetext{
${ }^{30}$ Besides the inclusion of the relative path of the current unemployment rate and the corresponding interaction terms with labor market experience, the model specification is exactly the same as in our baseline model (see column 3 of table 3 ).
} 
with $\Delta \ln \left(u r_{j t}\right) \equiv\left[\ln \left(u r_{j t}-\ln \left(u r_{j}^{0}\right)\right]\right.$. This variable captures the path of the current unemployment rate relative to the initial unemployment rate for a given entry cohort. We include the difference between current and initial unemployment as well as the interaction of this difference with potential labor market experience as additional regressors. As a consequence, by conditioning on the relative path of the unemployment rate from the year of entry onwards we simulate a hypothetical situation of persistent differences in unemployment, which is what we are after. Also note that we do not want to condition on the current unemployment rate in general because of the high collinearity between initial and current unemployment one the one side, making it difficult to back out the marginal effect of the initial unemployment rate. On the other side, the path of the unemployment rate, i.e. the path of the business cycle, may also be regarded as part of the outcome for entering the labor market at a given initial state. Thus, conditioning on the current unemployment rate would induce biased estimates as a result of controlling on part of the outcome.

\section{Figure 10}

Figure 10 shows predicted wage for the different hypothetical cohorts (the corresponding estimates are given in the last column of table 6 ). First, figure 10 shows that the short-run effect is more or less unchanged (as it should be). In contrast, however, the striking feature of figure 10 is that the differences in wage profiles across the three hypothetical cohorts do not really vanish over time, although they decrease somewhat at the highest levels of experience. The estimated loss in lifetime earnings accumulates to about $50 \%$ in this hypothetical situation of persistent differences in initial labor market conditions. Although this figure is highly abstract and stylized, is still nicely illustrates the importance of cyclical fluctuations on wage differentials across entry cohorts. Also, although this mechanism seems pretty obvious, we are not aware that this point has been explicitly made in the relevant literature so far.

\section{Figure 11}

Finally, figure 11 shows the estimated elasticities of outcome $\omega$ with respect to the initial unemployment rate, conditional on the path of the current unemployment rate (as before, relative to the level in the year of entry for any given cohort). ${ }^{31}$ We clearly see that the absence

\footnotetext{
${ }^{31}$ Note that figure 11 is identical to figure 7 , except that the path of the current unemployment rate is used as an additional regressor in estimating the parameters.
} 
of any cyclical movement at the macroeconomic level would lead to large and permanent differences in both mobility and employment patterns. Specifically, panels (a) and (b) show that cohorts faced with permanently higher unemployment would suffer from lower mobility, both across firms and across industries. They would, however, also face lower risk of dropping out of the labor force permanently, as shown in panel (c). Panels (d) and (e) show the expected effects on the annual number of days spent in employment and unemployment, respectively. Overall, because unemployment increases while employment decreases permanently, there results a strong negative effect on workers' job tenure (see panel (f)).

\section{Conclusions}

We study the long-run effects of initial economic conditions on wages, using a large sample of male workers entering the Austrian labor market sometime between 1978 and 2000. From the population of all labor market entrants, we have chosen to study those workers who presumably have completed secondary schooling only. Consistent with previous evidence, we find a robust negative effect of the initial unemployment rate on starting wages. This initial negative effect persists for the first few years after entry but then it appears to fade away afterwards. Even though wages catch up in the longer run, the initial negative effect and the persistence of this effect imply quite substantial effects on the present discounted value of lifetime earnings from entering the labor market during high unemployment. Our baseline model yields an estimated loss in the present discounted value of lifetime earnings of about $15 \%$, comparing a hypothetical cohort entering the labor force when unemployment is high with a cohort entering in times of average conditions.

We also find evidence for positive sample selection over the business cycle. That is, we find that labor market cohorts characterized by high initial unemployment are a positively selected groups of workers. However, we also show that such compositional effects are not able to explain away entry conditions' effects on wages. To the contrary, taking such compositional effects with respect to entry cohorts into account makes the short-run effect even larger and the long-run effect quite a bit more persistent. To correctly quantify the costs of business cycle fluctuations on labor market entrants, these compositional effects - which are mainly channelled through delayed entry into the labor force by registering for unemployment benefits 
for example - would have to be taken into account as well.

We further show that the short-run effect of bad entry conditions is much smaller for bluecollar than for white-collar workers and that the initial negative effect is much less persistent for the former group, implying much smaller overall losses in lifetime earnings for blue- than for white-collar workers. Thus blue-collar workers' wages are much more flexible than the wages of white-collar workers with a comparable level of education and training. This may imply that features of internal markets such as incentive payments, for example, are more important for white-collar workers than for blue-collar workers.

Finally we find that cohorts who first enter the labor force in unfavorable economic conditions differ in both their mobility and employment patterns, both of which in turn explain part of the long-term adjustment of wages. We find that entering the labor market during a recession has an initial negative impact on workers' mobility, but a countervailing positive effect on employment continuity and job tenure with the current employer. Overall, changes in mobility, employment and tenure patterns that are induced by the initial unemployment rate appear to cushion some of the initial negative effect on wages however. In line with previous evidence, we also find that cyclical patterns in the business cycle are the key element behind the long-term adjustment of entry cohorts' wages, both through their indirect effects on mobility and tenure and through any direct effects on aggregate wages. 


\section{References}

Abowd, J., Kramarz, F., and Margolis, D. (1999). High wage workers and high wage firms. Econmetrica, 67(2), 251-333.

Bachmann, R., Bauer, T. K., and David, P. (2009). Cohort Wage Effects and Job Mobility Evidence from German Linked Employer-Employee Data. Mimeo, RWI Essen.

Baker, G., Gibbs, M., and Holmstrom, B. (1994a). The Internal Economics of the Firm: Evidence from Personnel Data. Quarterly Journal of Economics, 109(4), 881-919.

Baker, G., Gibbs, M., and Holmstrom, B. (1994b). The Wage Policy of a Firm. Quarterly Journal of Economics, 109(4), 921-921.

Beaudry, P. and DiNardo, J. (1991). The Effect of Implicit Contracts on the Movement of Wages Over the Business Cycle: Evidence from Micro Data. Journal of Political Economy, 99(4), 665 .

Bertrand, M., Duflo, E., and Mullainathan, S. (2004). How Much Should We Trust Differencesin-Differences Estimates? Quarterly Journal of Economics, 119(1), 249-275.

Bils, M. (1985). Real Wages over the Business Cycle: Evidence from Panel Data. The Journal of Political Economy, 93(4), 666.

Blanchflower, D. and Oswald, A. (1990). The Wage Curve. The Scandinavian Journal of Economics, 92(2), 215-235.

Blundell, R., Reed, H., and Stoker, T. (2003). Interpreting aggregate wage growth: The role of labor market participation. American Economic Review, 93(4), 1114-1131.

Bowlus, A. (1995). Matching workers and jobs: Cyclical fluctuations in match quality. Journal of Labor Economics, 13(2), 335-350.

Breen, R. (2005). Explaining Cross-national Variation in Youth Unemployment Market and Institutional Factors. European Sociological Review, 21(2), 125-134.

Bundeskammer für Arbeiter und Angestellte (1980-2003). Wirtschafts- und Sozialstatistisches Taschenbuch.

Burgess, S., Propper, C., Rees, H., and Shearer, A. (2003). The class of 1981: the effects of early career unemployment on subsequent unemployment experiences. Labour Economics, 10(3), 291-309.

Cameron, A., Gelbach, J., and Miller, D. (2006). Robust Inference with Multi-Way Clustering. NBER Working Paper No. T0327.

Card, D. and Lemieux, T. (2000). Dropout and enrollment trends in the post-war period: what went wrong in the 1970s? NBER Working Paper No. 7658.

Dellas, H. and Sakellaris, P. (2003). On the cyclicality of schooling: theory and evidence. Oxford Economic Papers, 55(1), 148.

Devereux, P. (2000). Task assignment over the business cycle. Journal of Labor Economics, 18(1), 98-124. 
Devereux, P. and Hart, R. (2006). Real wage cyclicality of job stayers, within-company job movers, and between-company job movers. Industrial and Labor Relations Review, 60(1), $105-119$.

Dohmen, T. (2004). Performance, seniority, and wages: formal salary systems and individual earnings profiles. Labour Economics, 11(6), 741-763.

Federal Ministry for Education, the Arts and Culture (2008). Development of Education in Austria, 2004-2007.

Flabbi, L. and Ichino, A. (2001). Productivity, seniority and wages: new evidence from personnel data. Labour Economics, 8(3), 359-387.

Freeman, R. (1981). Career Patterns of College Graduates in a Declining Job Market. NBER Working Paper No. 750.

Gardecki, R. and Neumark, D. (1998). Order from chaos? The effects of early labor market experiences on adult labor market outcomes. Industrial and Labor Relations Review, 51(2), 299-322.

Genda, Y., Kondo, A., and Ohta, S. (2009). Long-Term Effects of a Recession at Labor Market Entry in Japan and the United States. Journal of Human Resources, forthcoming.

Gibbons, R. and Waldman, M. (1999). A Theory of Wage and Promotion Dynamics Inside Firms. Quarterly Journal of Economics, 114(4), 1321-1358.

Gibbons, R. and Waldman, M. (2006). Enriching a theory of wage and promotion dynamics inside firms. Journal of Labor Economics, 24(1), 59-107.

Giuliano, P. and Spilimbergo, A. (2009). Growing Up in a Recession: Beliefs and the Macroeconomy. NBER Working Papers.

Gruetter, M. and Lalive, R. (2009). The importance of firms in wage determination. Labour Economics, 16(2), 149-160.

Guadalupe, M. (2007). Product market competition, returns to skill, and wage inequality. Journal of Labor Economics, 25(3), 439-474.

Gustman, A. and Steinmeier, T. (1981). The Impact of Wages and Unemployment on Youth Enrollment and Labor Supply. The Review of Economics and Statistics, 63(4), 553-560.

Haefke, C., Sonntag, M., and van Rens, T. (2008). Wage rigidity and job creation. IZA Discussion Paper No. 3714.

Hofer, H. and Weber, A. (2002). Wage mobility in Austria 1986-1996. Labour Economics, $\mathbf{9}(4), 563-577$.

Kahn, L. B. (2009). The Long-Term Labor Market Consequences of Graduating from College in a Bad Economy. Labour Economics, forthcoming.

Kondo, A. (2007). Does the first job really matter? State dependency in employment status in Japan. Journal of the Japanese and International Economies, 21(3), 379-402.

Kondo, A. (2008). Differential Effects of Gradudating During a Recession Across Race and Gender. ISERP working paper no. 0809-08. 
Kwon, I. and Meyersson Milgrom, E. M. (2007). Cohort Effects in Wages and Promotions. SIEPR Discussion Paper No. 07-25.

Lazear, E. (1979). Why is there mandatory retirement? The Journal of Political Economy, $\mathbf{8 7}(6), 1261$.

Lazear, E. and Oyer, P. (2004). Internal and external labor markets: a personnel economics approach. Labour Economics, 11(5), 527-554.

Lazear, E. and Rosen, S. (1981). Rank-order tournaments as optimum labor contracts. The Journal of Political Economy, 89(5), 841.

Lazear, E. and Shaw, K. (2008). The structure of wages: An international comparison. University of Chicago Press.

Manning, A. (2003). Monopsony in motion: Imperfect competition in labor markets. Princeton University Press.

Mortensen, D. (2003). Wage dispersion: why are similar workers paid differently? The MIT Press.

Moulton, B. (1986). Random Group Effects and the Precision of Regression Estimates. Journal of Econometrics, 32(3), 385-397.

Murphy, K. and Welch, F. (1990). Empirical Age-Earnings Profiles. Journal of Labor Economics, $\mathbf{8}(2), 202$.

Neal, D. (1995). Industry-specific human capital: Evidence from displaced workers. Journal of labor Economics, 13(4), 653-677.

Neumark, D. (2002). Youth labor markets in the United States: Shopping around vs. staying put. Review of Economics and Statistics, 84(3), 462-482.

Nijkamp, P., Poot, J., and Zealand, H. (2005). The last word on the wage curve? Journal of Economic Surveys, 19(3), 421-450.

Oreopoulos, P., von Wachter, T., and Heisz, A. (2006). The Short-and Long-Term Career Effects of Graduating in a Recession: Hysteresis and Heterogeneity in the Market for College Graduates. NBER Working Paper No. 12159.

Oreopoulos, P., von Wachter, T., and Heisz, A. (2008). The Short-and Long-Term Career Effects of Graduating in a Recession: Hysteresis and Heterogeneity in the Market for College Graduates. IZA Discussion Paper No. 3578.

Oyer, P. (2006). Initial Labor Market Conditions and Long-Term Outcomes for Economists. The Journal of Economic Perspectives, 20(3), 143-160.

Oyer, P. (2008). The Making of an Investment Banker: Stock Market Shocks, Career Choice, and Lifetime Income. The Journal of Finance, 63(6), 2601-2628.

Raaum, O. and Roed, K. (2006). Do Business Cycle Conditions at the Time of Labor Market Entry Affect Future Employment Prospects? The Review of Economics and Statistics, 88(2), 193-210.

Raferzeder, T. and Winter-Ebmer, R. (2007). Who is on the rise in Austria: Wage mobility and mobility risk. Journal of Economic Inequality, 5(1), 39-51. 
Rodgers, W. L. (1982). Estimable Functions of Age, Period, and Cohort Effects. American Sociological Review, 47(6), 774-787.

Ryan, P. (2001). The School-to-Work Transition: A Cross-National Perspective. Journal of Economic Literature, 39(1), 34-92.

Saks, R. and Wozniak, A. (2007). Labor Reallocation over the Business Cycle: New Evidence from Internal Migration. IZA Discussion Paper No. 2766.

Schwerdt, G., Ichino, A., Ruf, O., Winter-Ebmer, R., and Zweimüller, J. (2009). Does the color of the collar matter? Firm specific human capital and post-displacement outcomes. Economics Letters, forthcoming.

Seltzer, A. and Merrett, D. (2000). Personnel policies at the union bank of Australia: evidence from the 1888-1900 entry cohorts. Journal of Labor Economics, 18(4), 573-613.

Solon, G., Barsky, R., and Parker, J. (1994). Measuring the Cyclicality of Real Wages: How Important is Composition Bias. The Quarterly Journal of Economics, 109(1), 1-25.

Stiglbauer, A., Stahl, F., Winter-Ebmer, R., and Zweimüller, J. (2003). Job Creation and Job Destruction in a Regulated Labor Market: The Case of Austria. Empirica, 30(2), 127-148.

Sullivan, P. (2009). Empirical Evidence on Occupation and Industry Specific Human Capital. Labour Economics, forthcoming.

Topel, R. H. and Ward, M. P. (1992). Job Mobility and the Careers of Young Men. Quarterly Journal of Economics, 107, 439-479.

Treble, J., van Gameren, E., Bridges, S., and Barmby, T. (2001). The internal economics of the firm: further evidence from personnel data. Labour Economics, 8(5), 531-552.

van Reenen, J. (1996). The creation and capture of rents: wages and innovation in a panel of UK companies. The Quarterly Journal of Economics, 111(1), 195-226.

von Wachter, T. and Bender, S. (2008). Do Initial Conditions Persist between Firms? An Analysis of Firm-Entry Cohort Effects and Job Losers Using Matched Employer-Employee Data. In S. Bender, J. Lane, K. L. Shaw, F. Andersson, and T. von Wachter, editors, The Analysis of Firms and Employees. Quantitative and Qualitative Approaches, pages 135-162. National Bureau of Economic Research.

Winter-Ebmer, R. (1996). Wage curve, unemployment duration and compensating differentials. Labour Economics, 3(4), 425-434.

Wooldridge, J. (2003). Cluster-Sample Methods in Applied Econometrics. American Economic Review, 93(2), 133-138.

Wozniak, A. (2006). Educational Differences in the Migration Responses of Young Workers to Local Labor Market Conditions. IZA discussion paper no. 1954.

Zweimüller, J., Winter-Ebmer, R., Lalive, R., Kuhn, A., Ruf, O., Wuellrich, J.-P., and Büchi, S. (2009). The Austrian Social Security Database (ASSD). NRN: The Austrian Center for Labor Economics and the Analysis of the Welfare State, Working Paper 0903. 
Table 1: Sample selection

\begin{tabular}{|c|c|c|c|c|c|c|}
\hline \multirow[b]{3}{*}{ Age at start of first job } & \multicolumn{6}{|c|}{ Age at start of first regular employment } \\
\hline & \multicolumn{2}{|c|}{$15-30$} & \multicolumn{2}{|c|}{$15-21$} & \multicolumn{2}{|c|}{$22-30$} \\
\hline & 20.760 & $(3.010)$ & 19.097 & $(1.160)$ & 24.386 & $(2.589)$ \\
\hline Duration of first regular job & 2.807 & $(3.983)$ & 2.705 & $(4.016)$ & 3.030 & $(3.900)$ \\
\hline Blue-collar & 0.650 & $(0.477)$ & 0.724 & $(0.447)$ & 0.487 & $(0.500)$ \\
\hline White-collar & 0.348 & $(0.476)$ & 0.273 & $(0.446)$ & 0.510 & $(0.500)$ \\
\hline Nominal daily wage & 34.805 & $(16.142)$ & 31.774 & (13.639) & 41.411 & $(18.957)$ \\
\hline Real daily wage & 50.106 & $(18.747)$ & 47.062 & $(15.491)$ & 56.742 & $(23.027)$ \\
\hline Below GfGr: Yes = 1 & 0.064 & $(0.244)$ & 0.058 & $(0.233)$ & 0.077 & $(0.266)$ \\
\hline Above HBGr: Yes $=1$ & 0.048 & $(0.213)$ & 0.018 & $(0.133)$ & 0.112 & $(0.315)$ \\
\hline \multicolumn{7}{|l|}{ Region of employer: } \\
\hline Vienna & 0.239 & $(0.426)$ & 0.198 & $(0.399)$ & 0.326 & $(0.469)$ \\
\hline Lower Austria & 0.157 & $(0.364)$ & 0.170 & $(0.376)$ & 0.129 & $(0.336)$ \\
\hline Burgenland & 0.024 & $(0.152)$ & 0.025 & $(0.156)$ & 0.021 & $(0.142)$ \\
\hline Upper Austria & 0.169 & $(0.375)$ & 0.184 & $(0.388)$ & 0.137 & $(0.344)$ \\
\hline Styria & 0.139 & $(0.346)$ & 0.144 & $(0.351)$ & 0.129 & $(0.335)$ \\
\hline Carinthia & 0.064 & $(0.245)$ & 0.065 & $(0.247)$ & 0.062 & $(0.241)$ \\
\hline Salzburg & 0.070 & $(0.255)$ & 0.071 & $(0.257)$ & 0.067 & $(0.249)$ \\
\hline Tyrol & 0.090 & $(0.287)$ & 0.092 & $(0.289)$ & 0.087 & $(0.282)$ \\
\hline Vorarlberg & 0.048 & $(0.214)$ & 0.051 & $(0.219)$ & 0.042 & $(0.201)$ \\
\hline \multicolumn{7}{|l|}{ Industry of employer: } \\
\hline Agriculture & 0.015 & $(0.121)$ & 0.012 & $(0.110)$ & 0.021 & $(0.142)$ \\
\hline Electricity & 0.007 & $(0.084)$ & 0.009 & $(0.094)$ & 0.003 & $(0.057)$ \\
\hline Mining & 0.006 & $(0.078)$ & 0.007 & $(0.082)$ & 0.005 & $(0.068)$ \\
\hline Manufacturing & 0.344 & $(0.475)$ & 0.399 & $(0.490)$ & 0.225 & $(0.417)$ \\
\hline Construction & 0.164 & $(0.371)$ & 0.188 & $(0.390)$ & 0.114 & $(0.318)$ \\
\hline Wholesale and retail trade & 0.149 & $(0.356)$ & 0.157 & $(0.364)$ & 0.130 & $(0.336)$ \\
\hline Gastronomy, hotel business & 0.059 & $(0.236)$ & 0.045 & $(0.208)$ & 0.089 & $(0.285)$ \\
\hline Transportation & 0.061 & $(0.240)$ & 0.063 & $(0.243)$ & 0.057 & $(0.233)$ \\
\hline Finance & 0.081 & $(0.273)$ & 0.058 & $(0.235)$ & 0.130 & $(0.337)$ \\
\hline Cleaning, body care & 0.009 & $(0.096)$ & 0.008 & $(0.089)$ & 0.012 & $(0.109)$ \\
\hline Arts, entertainment, sports & 0.010 & $(0.101)$ & 0.005 & $(0.072)$ & 0.021 & $(0.145)$ \\
\hline Healthcare, welfare & 0.014 & $(0.116)$ & 0.007 & $(0.081)$ & 0.029 & $(0.167)$ \\
\hline Education, research & 0.015 & $(0.121)$ & 0.005 & $(0.070)$ & 0.037 & $(0.189)$ \\
\hline Lobbies, social security agencies & 0.064 & $(0.244)$ & 0.035 & $(0.185)$ & 0.125 & $(0.331)$ \\
\hline Housekeeping & 0.001 & $(0.029)$ & 0.000 & $(0.022)$ & 0.002 & $(0.040)$ \\
\hline Number of observations & \multicolumn{2}{|c|}{$1,197,704$} & \multicolumn{2}{|c|}{821,028} & \multicolumn{2}{|c|}{376,676} \\
\hline
\end{tabular}

Notes: Table entries are sample means and standard deviations (in parentheses). Daily wages are given in Euros, and real wage are deflated using the consumer price index with base year 2007. GfGr ("Gerinfügigkeitsgrenze") and HBGr ("Höchstbemessungsgrundlage") denotes the upper and the lower censoring point, respectively. Below GfGr is an indicator taking on the value 1 if the nominal daily wage is equal to or below 1.2 times the lower censoring point and 0 otherwise. Above HBGr is an indicator taking on the value 1 if the nominal daily wage is equal to or above 0.8 times the upper censoring point and 0 otherwise. 
Table 2: Summary statistics

\begin{tabular}{|c|c|c|}
\hline & Mean & Standard deviation \\
\hline \multicolumn{3}{|l|}{ Individual characteristics: } \\
\hline Real daily wage & 47.834 & 15.572 \\
\hline Nominal daily wage & 33.054 & 13.965 \\
\hline Below GfGr: Yes = 1 & 0.052 & 0.222 \\
\hline Above HBGr: Yes $=1$ & 0.018 & 0.135 \\
\hline Age at start of first regular job & 19.097 & 1.154 \\
\hline Age at first entry into the labor force & 18.574 & 1.527 \\
\hline Duration of first regular job & 2.853 & 4.317 \\
\hline Any unemployment before first job: Yes $=1$ & 0.302 & 0.459 \\
\hline Unemployment days before first job & 41.984 & 100.403 \\
\hline Blue-collar worker & 0.745 & 0.436 \\
\hline White-collar worker & 0.253 & 0.435 \\
\hline \multicolumn{3}{|l|}{ Aggregate-level variables: } \\
\hline State-level unemployment rate & 6.551 & 2.909 \\
\hline District-level unemployment rate & 6.609 & 3.166 \\
\hline Number of entrants, age $15-21$ & $3,763.821$ & $1,453.704$ \\
\hline \multicolumn{3}{|l|}{ Firm-level characteristics: } \\
\hline Size of firm (in 100's) & 5.912 & 25.083 \\
\hline Female share of workforce & 0.246 & 0.221 \\
\hline Number of quarters per year & 3.941 & 0.340 \\
\hline \multicolumn{3}{|l|}{ Region of employer: } \\
\hline Vienna & 0.179 & 0.383 \\
\hline Lower Austria & 0.171 & 0.377 \\
\hline Burgenland & 0.025 & 0.156 \\
\hline Upper Austria & 0.195 & 0.396 \\
\hline Styria & 0.146 & 0.353 \\
\hline Carinthia & 0.066 & 0.249 \\
\hline Salzburg & 0.071 & 0.256 \\
\hline Tyrol & 0.093 & 0.291 \\
\hline Vorarlberg & 0.054 & 0.227 \\
\hline \multicolumn{3}{|l|}{ Industry of employer: } \\
\hline Agriculture & 0.011 & 0.102 \\
\hline Electricity & 0.010 & 0.099 \\
\hline Mining & 0.008 & 0.087 \\
\hline Manufacturing & 0.419 & 0.493 \\
\hline Construction & 0.200 & 0.400 \\
\hline Wholesale and retail trade & 0.158 & 0.364 \\
\hline Gastronomy, hotel business & 0.043 & 0.203 \\
\hline Transportation & 0.040 & 0.195 \\
\hline Finance & 0.059 & 0.236 \\
\hline Cleaning, body care & 0.008 & 0.088 \\
\hline Arts, entertainment, sports & 0.005 & 0.071 \\
\hline Healthcare, welfare & 0.007 & 0.084 \\
\hline Education, research & 0.005 & 0.071 \\
\hline Lobbies, social security agencies & 0.028 & 0.164 \\
\hline Housekeeping & 0.000 & 0.020 \\
\hline Number of observations & \multicolumn{2}{|r|}{223,900} \\
\hline
\end{tabular}

Notes: The two unemployment rates are computed from the raw data of the ASSD. See also notes of table 1 . 
Table 3: The long-run effects of initial labor market shock on wages

\begin{tabular}{|c|c|c|c|c|}
\hline \multirow{3}{*}{$\begin{array}{l}\text { Mean } \\
\text { Standard deviation }\end{array}$} & \multicolumn{4}{|c|}{ ln(real daily wage) } \\
\hline & \multicolumn{4}{|c|}{4.250} \\
\hline & \multicolumn{4}{|c|}{0.386} \\
\hline $\ln \left(u r^{0}\right)$ & $\begin{array}{c}-0.026 \\
(0.024)\end{array}$ & $\begin{array}{c}-0.045 \\
(0.028)\end{array}$ & $\begin{array}{c}-0.062^{\star \star} \\
(0.028)\end{array}$ & $\begin{array}{c}-0.075^{\star \star} \\
(0.032)\end{array}$ \\
\hline $\exp$ & $\begin{array}{l}0.114^{\star \star \star} \\
(0.015)\end{array}$ & $\begin{array}{l}0.119^{\star \star \star} \\
(0.016)\end{array}$ & $\begin{array}{l}0.119^{\star \star \star} \\
(0.015)\end{array}$ & $\begin{array}{l}0.138^{\star \star \star} \\
(0.025)\end{array}$ \\
\hline$e x p^{2}$ & $\begin{array}{l}-0.008^{\star \star \star} \\
(0.001)\end{array}$ & $\begin{array}{l}-0.009^{\star \star \star} \\
(0.001)\end{array}$ & $\begin{array}{l}-0.009^{\star \star \star} \\
(0.001)\end{array}$ & $\begin{array}{l}-0.009^{\star \star \star} \\
(0.002)\end{array}$ \\
\hline$e x p^{3}$ & $\begin{array}{l}0.000^{\star \star \star} \\
(0.000)\end{array}$ & $\begin{array}{l}0.000^{\star \star \star} \\
(0.000)\end{array}$ & $\begin{array}{l}0.000^{\star \star \star} \\
(0.000)\end{array}$ & $\begin{array}{l}0.000^{\star \star \star} \\
(0.000)\end{array}$ \\
\hline $\exp \cdot \ln \left(u r^{0}\right)$ & $\begin{array}{l}0.013^{\star \star \star} \\
(0.005)\end{array}$ & $\begin{array}{l}0.015^{\star \star \star} \\
(0.005)\end{array}$ & $\begin{array}{l}0.016^{\star \star \star} \\
(0.005)\end{array}$ & $\begin{array}{l}0.020^{\star \star \star} \\
(0.007)\end{array}$ \\
\hline$e x p^{2} \cdot \ln \left(u r^{0}\right)$ & $\begin{array}{l}-0.001^{\star \star \star} \\
(0.000)\end{array}$ & $\begin{array}{l}-0.001^{\star \star \star} \\
(0.000)\end{array}$ & $\begin{array}{l}-0.001^{\star \star \star} \\
(0.000)\end{array}$ & $\begin{array}{l}-0.002^{\star \star \star} \\
(0.001)\end{array}$ \\
\hline$e x p^{3} \cdot \ln \left(u r^{0}\right)$ & $\begin{array}{l}0.000^{\star \star \star} \\
(0.000)\end{array}$ & $\begin{array}{l}0.000^{\star \star \star} \\
(0.000)\end{array}$ & $\begin{array}{l}0.000^{\star \star \star} \\
(0.000)\end{array}$ & $\begin{array}{l}0.000^{\star \star \star} \\
(0.000)\end{array}$ \\
\hline$\varepsilon_{u r}^{y}(0)$ & $\begin{array}{l}-0.026 \\
(0.024)\end{array}$ & $\begin{array}{r}-0.045 \\
(0.028)\end{array}$ & $\begin{array}{r}-0.062 \\
(0.028)\end{array}$ & $\begin{array}{r}-0.075 \\
(0.032)\end{array}$ \\
\hline$\varepsilon_{u r}^{y}(5)$ & $\begin{array}{c}0.009 \\
(0.011)\end{array}$ & $\begin{array}{r}-0.001 \\
(0.013)\end{array}$ & $\begin{array}{l}-0.015 \\
(0.014)\end{array}$ & $\begin{array}{r}-0.010 \\
(0.012)\end{array}$ \\
\hline$\varepsilon_{u r}^{y}(10)$ & $\begin{array}{c}0.005 \\
(0.006)\end{array}$ & $\begin{array}{c}0.002 \\
(0.006)\end{array}$ & $\begin{array}{r}-0.011 \\
(0.007)\end{array}$ & $\begin{array}{c}0.004 \\
(0.009)\end{array}$ \\
\hline$\varepsilon_{u r}^{y}(15)$ & $\begin{array}{r}-0.007 \\
(0.005)\end{array}$ & $\begin{array}{r}-0.006 \\
(0.005)\end{array}$ & $\begin{array}{r}-0.019 \\
(0.005)\end{array}$ & $\begin{array}{r}-0.009 \\
(0.007)\end{array}$ \\
\hline$\varepsilon_{u r}^{y}(20)$ & $\begin{array}{c}0.001 \\
(0.007)\end{array}$ & $\begin{array}{c}0.005 \\
(0.009)\end{array}$ & $\begin{array}{r}-0.009 \\
(0.006)\end{array}$ & $\begin{array}{r}-0.021 \\
(0.008)\end{array}$ \\
\hline Regional controls & Yes & Yes & Yes & Yes \\
\hline Quadratic time trend & Yes & Yes & Yes & Yes \\
\hline State-specific trends & No & Yes & Yes & Yes \\
\hline Individual vars & No & No & Yes & Yes \\
\hline Experience $\times$ entry & No & No & No & Yes \\
\hline Number of observations & $3,455,895$ & $3,455,895$ & $3,455,895$ & $3,455,895$ \\
\hline Number of regressors & 18 & 34 & 61 & 64 \\
\hline Adjusted R-Squared & 0.286 & 0.287 & 0.360 & 0.361 \\
\hline p-value (F-statistic) & 0.000 & 0.000 & 0.000 & 0.000 \\
\hline
\end{tabular}

Notes: ${ }^{\star \star \star},{ }^{\star \star}$, and ${ }^{\star}$ denote statistical significance on the $1 \%, 5 \%$, and $10 \%$ level, respectively. Robust standard errors are given in parentheses and are clustered on both state and year. exp and $u r^{0}$ denote potential labor market experience (in years) and the initial unemployment rate, respectively. $\varepsilon_{u r}^{y}(k)$ denotes the estimated elasticity of wages with respect to the initial unemployment rate, evaluated at $k$ years of potential labor market experience. 


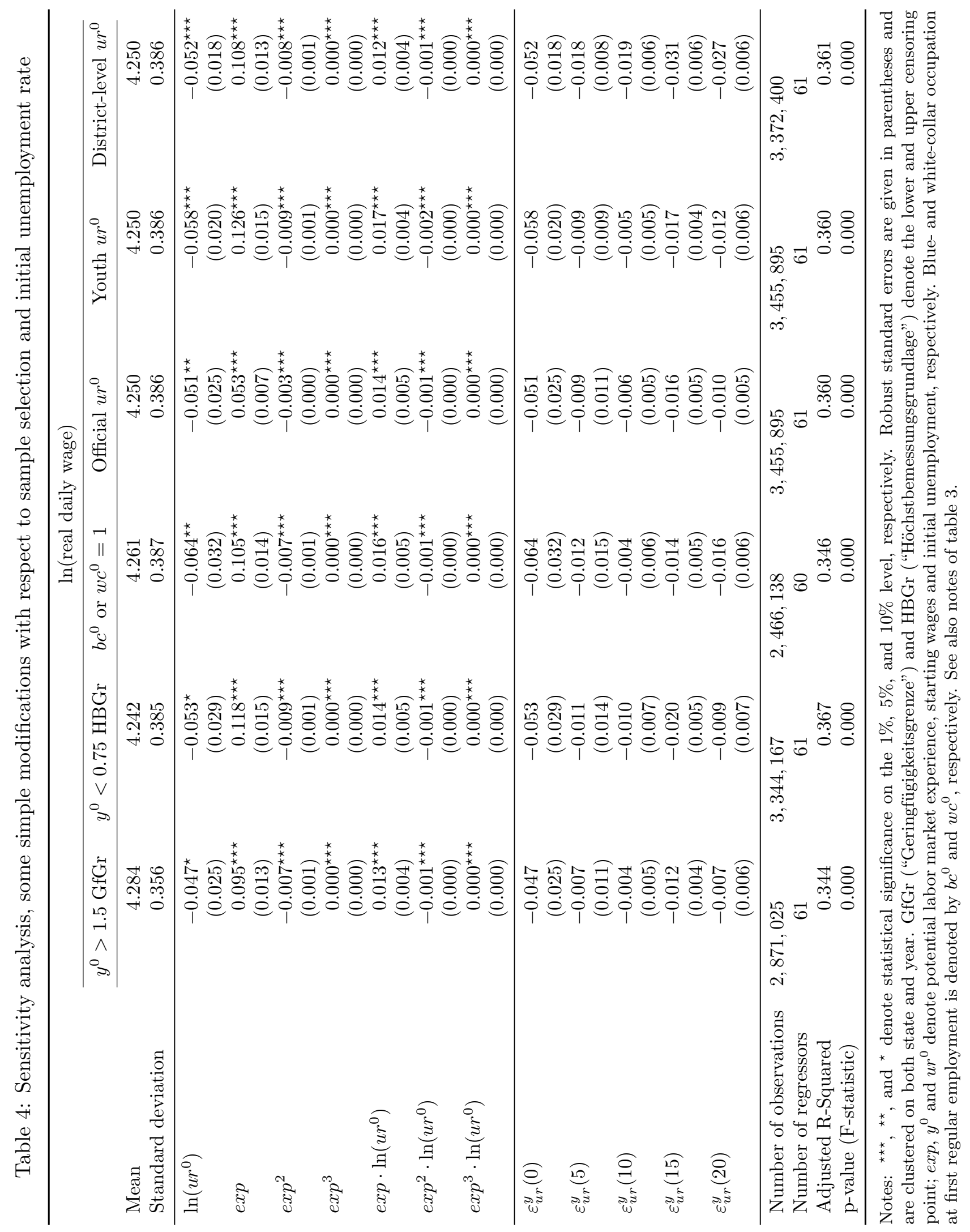




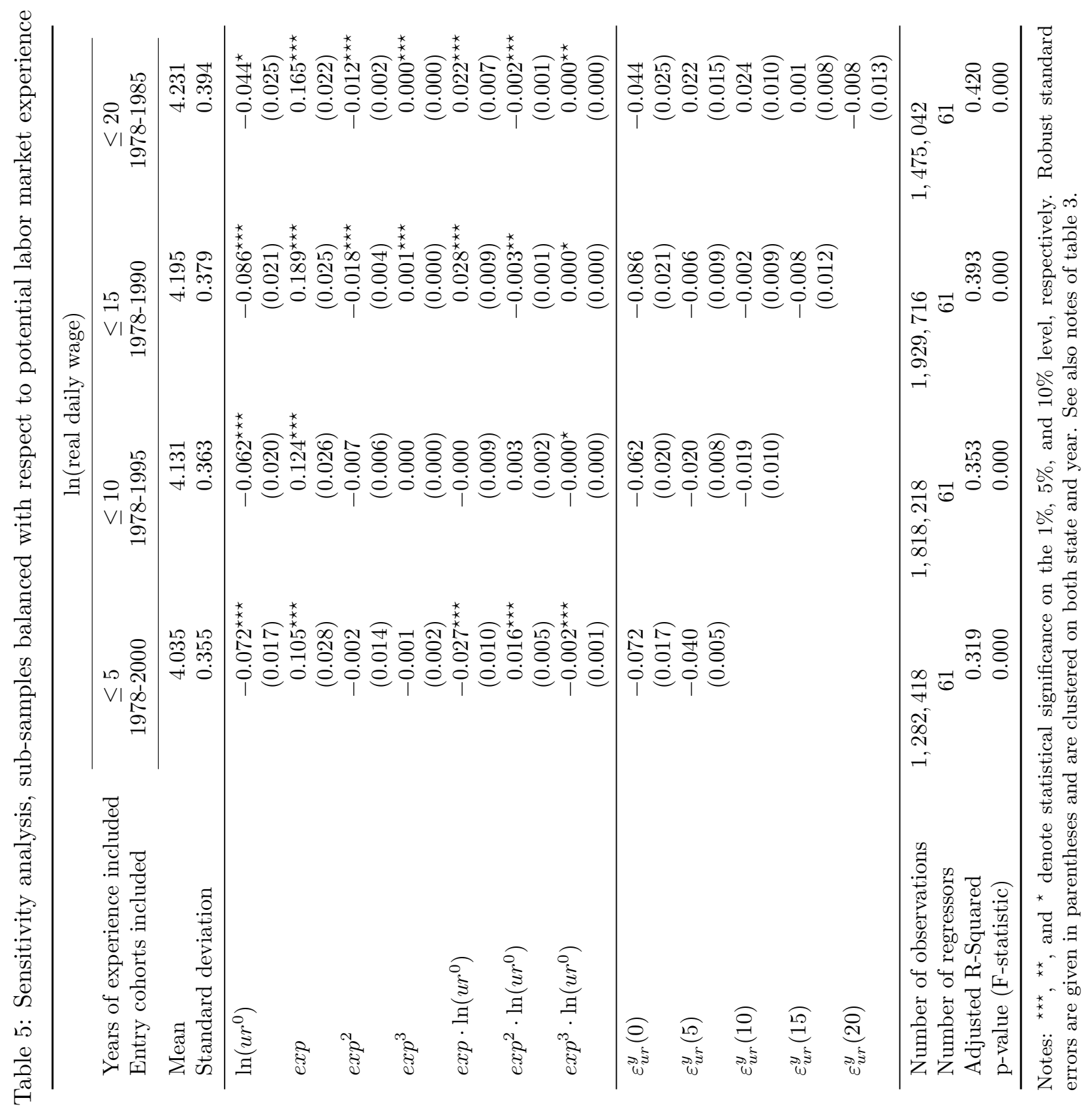




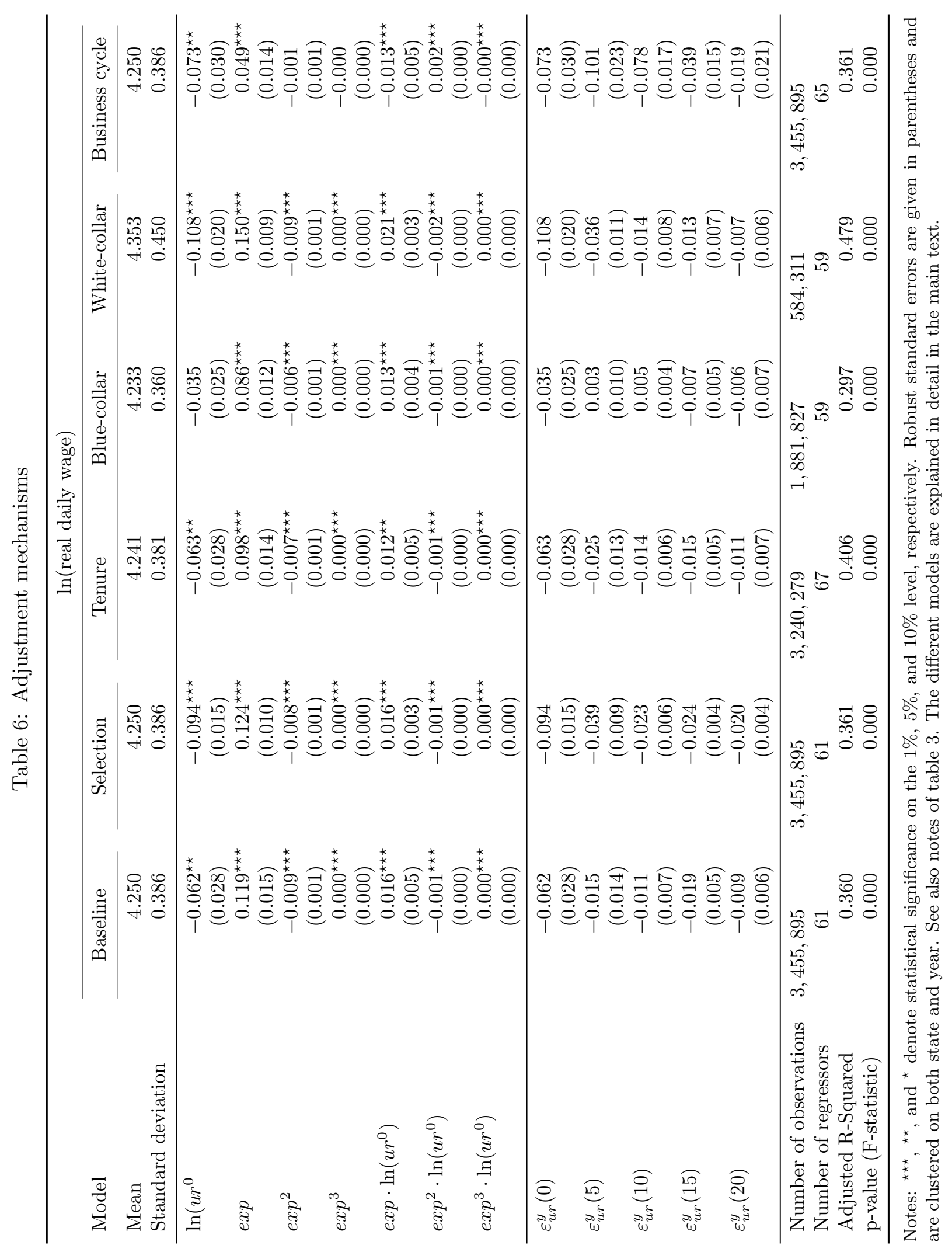


Figure 1: Long-run wage profiles, by labor market entry cohort

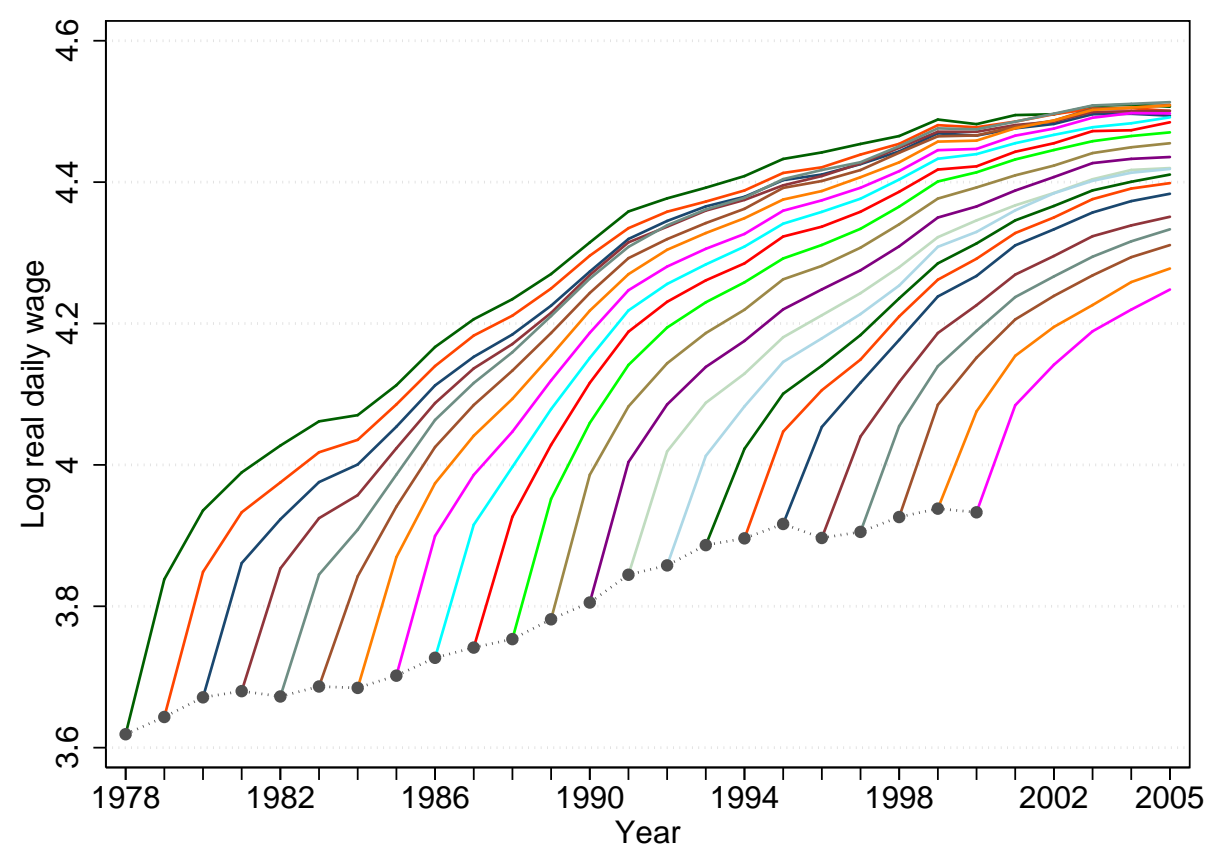

(a) Average log real daily wages

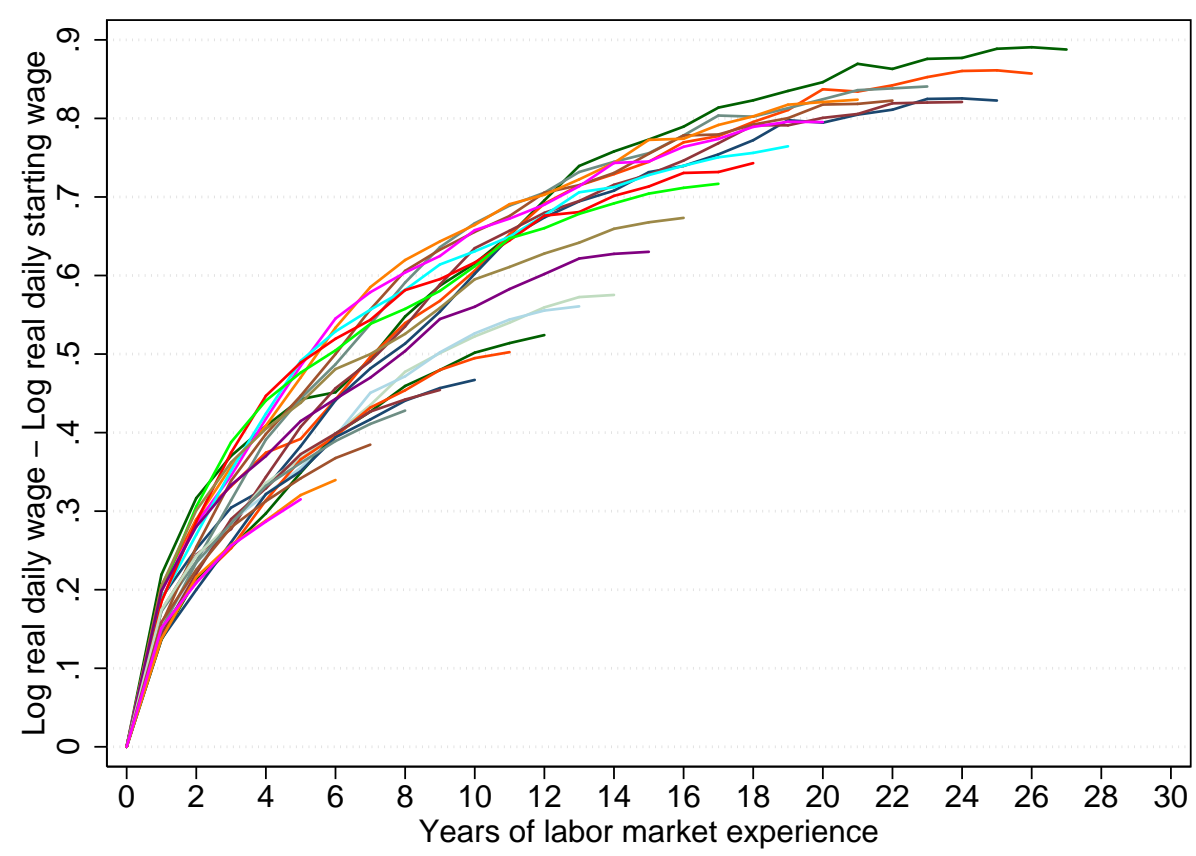

(b) Wage growth over potential labor market experience

Notes: Panel (a) shows average log real daily wages, separately for each labor market entry cohort. The black dots show average log starting wages for each labor-market entry cohort from 1978 until 2000. The black dotted line therefore highlights the evolution of starting wages over calendar time. The colored lines show entry cohorts' long-run wage profiles. The y-axis in panel (b) shows the average $\log$ real daily wage minus the log real daily starting wage of the corresponding entry cohort; panel (b) shows cohorts' approximate wage growth since first entry versus potential labor market experience. 
Figure 2: Fluctuations in local unemployment rates, by state

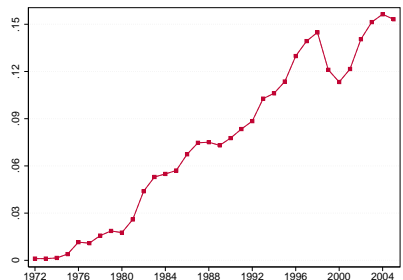

(a) Vienna

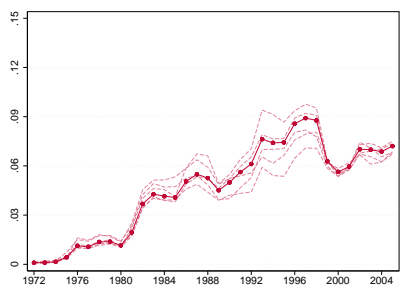

(d) Upper Austria

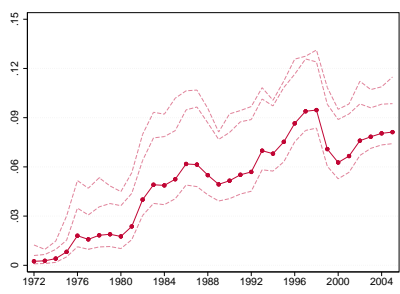

(g) Salzburg

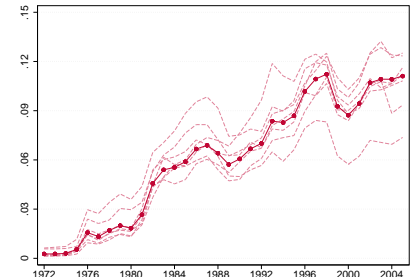

(b) Lower Austria

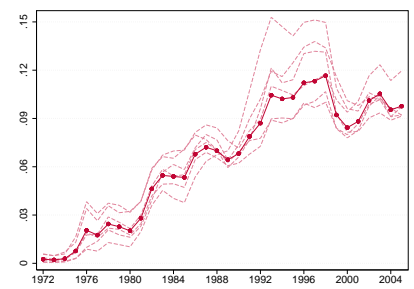

(e) Styria

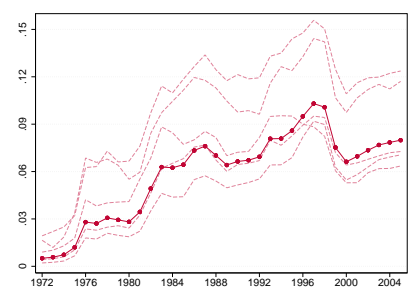

(h) Tyrol

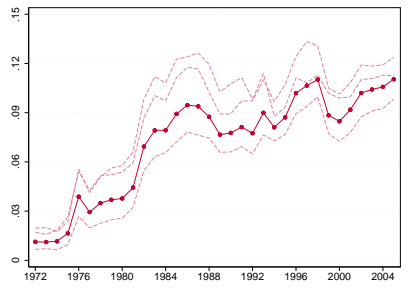

(c) Burgenland

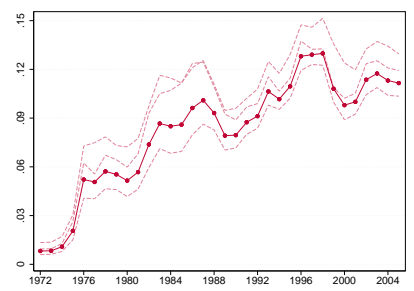

(f) Carinthia

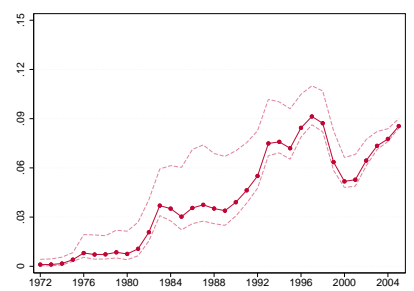

(i) Vorarlberg

Notes: The dashed lines show male unemployment rates at the level of the district ("Bezirk") and the filled dotted lines show the unemployment rate at the level of the state ("Bundesland"). Both rates have been computed from the individual-level data of the ASSD and both refer to male workers aged between 15 and 65 . See appendix A for details. 


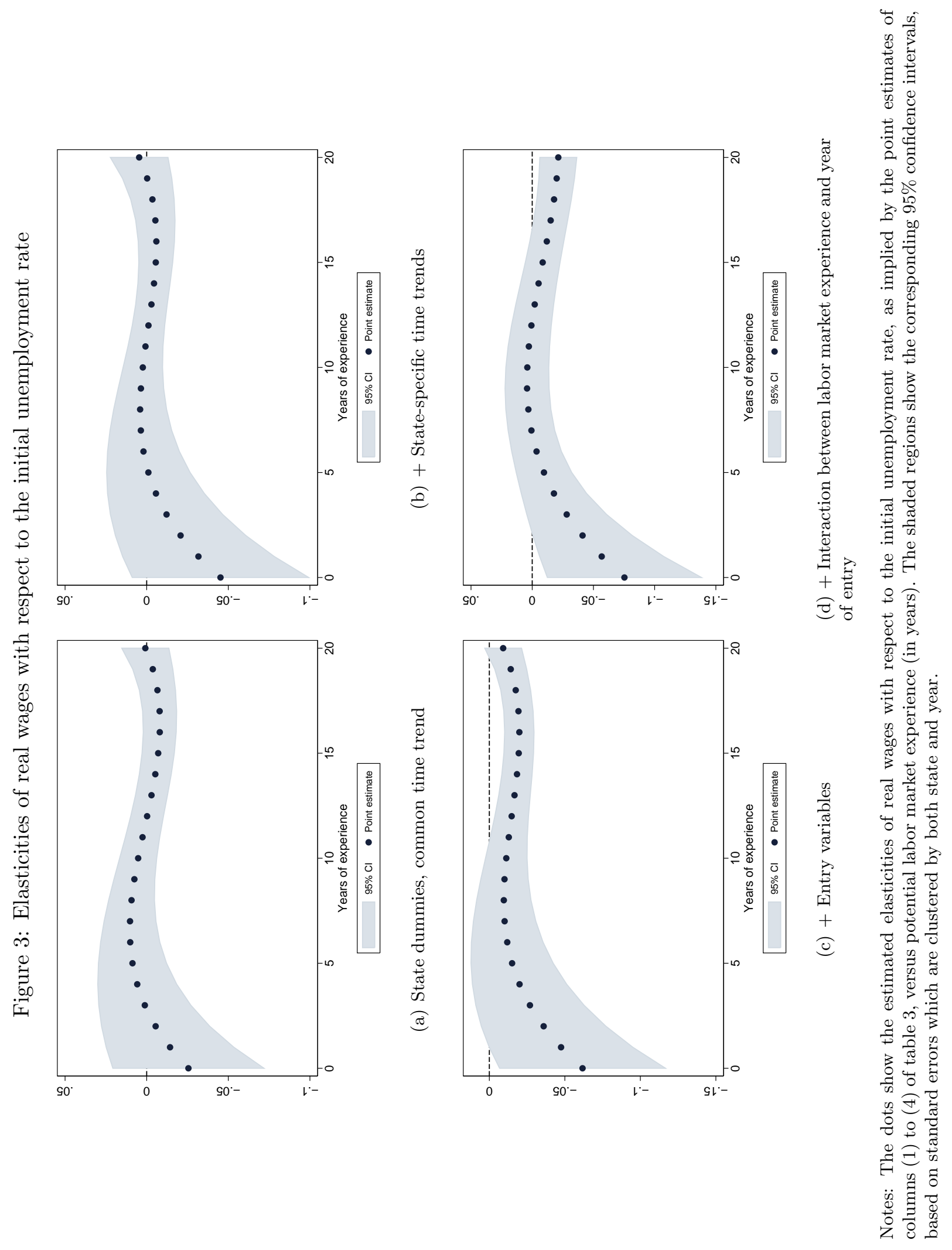


Figure 4: Predicted wage profiles for three hypothetical entry cohorts

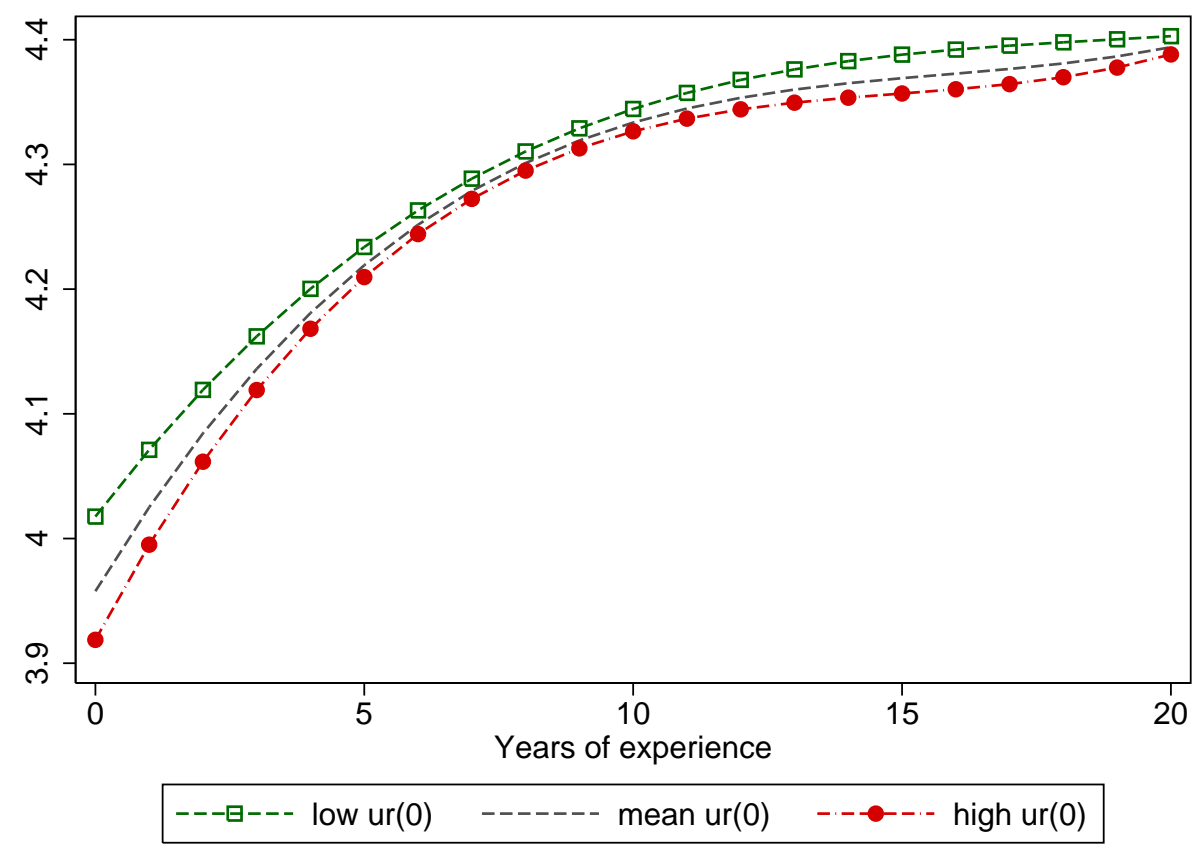

(a)

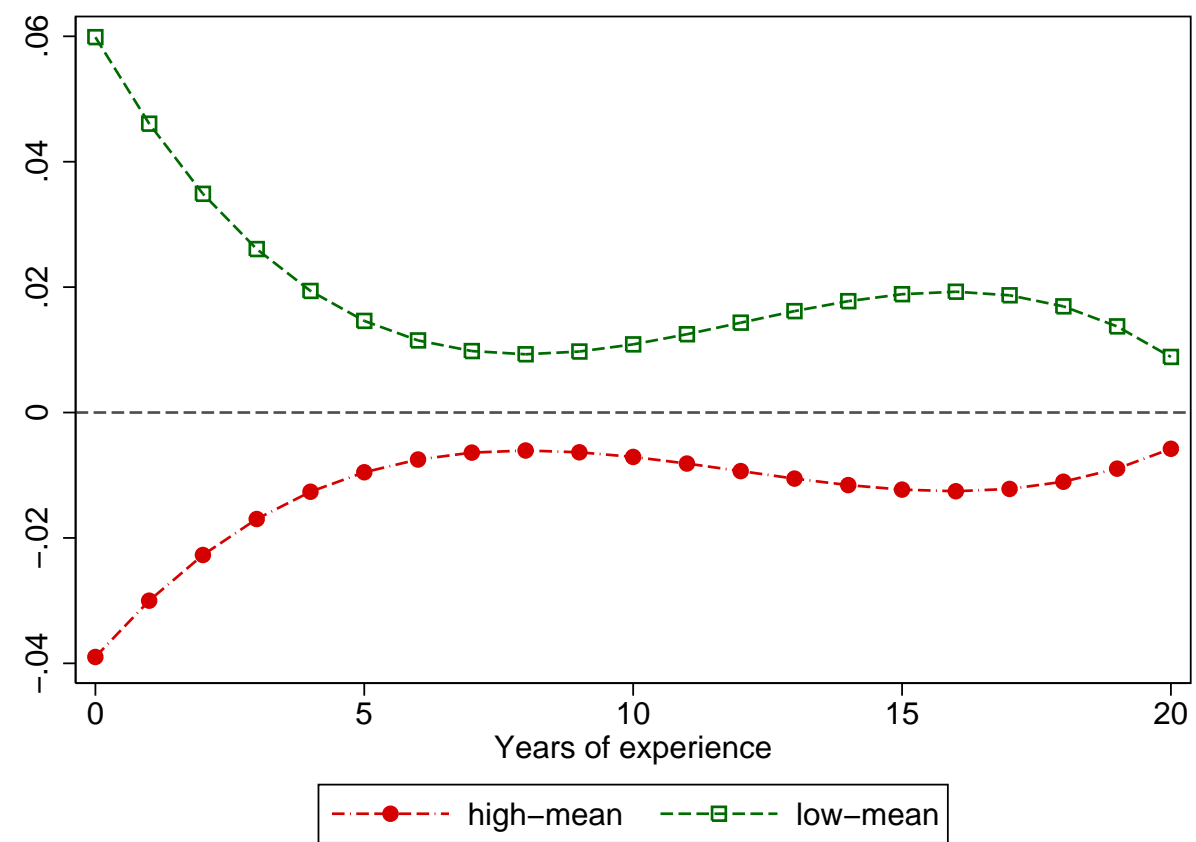

(b)

Notes: The figure in panel (a) shows predicted wage profiles for three different, hypothetical cohorts of labor market entrants. The dashed line shows the wage profile of a cohort entering at average initial conditions. The dotted red (squared green) line shows the wage profile of a cohort entering in a recession (a boom). Panel (b) shows the predicted wage profiles of the cohort entering in a recession or a boom - relative to the cohort entering the labor market at the average unemployment rate. See main text for details. 
Figure 5: Present discounted value of the loss (gain) in lifetime earnings

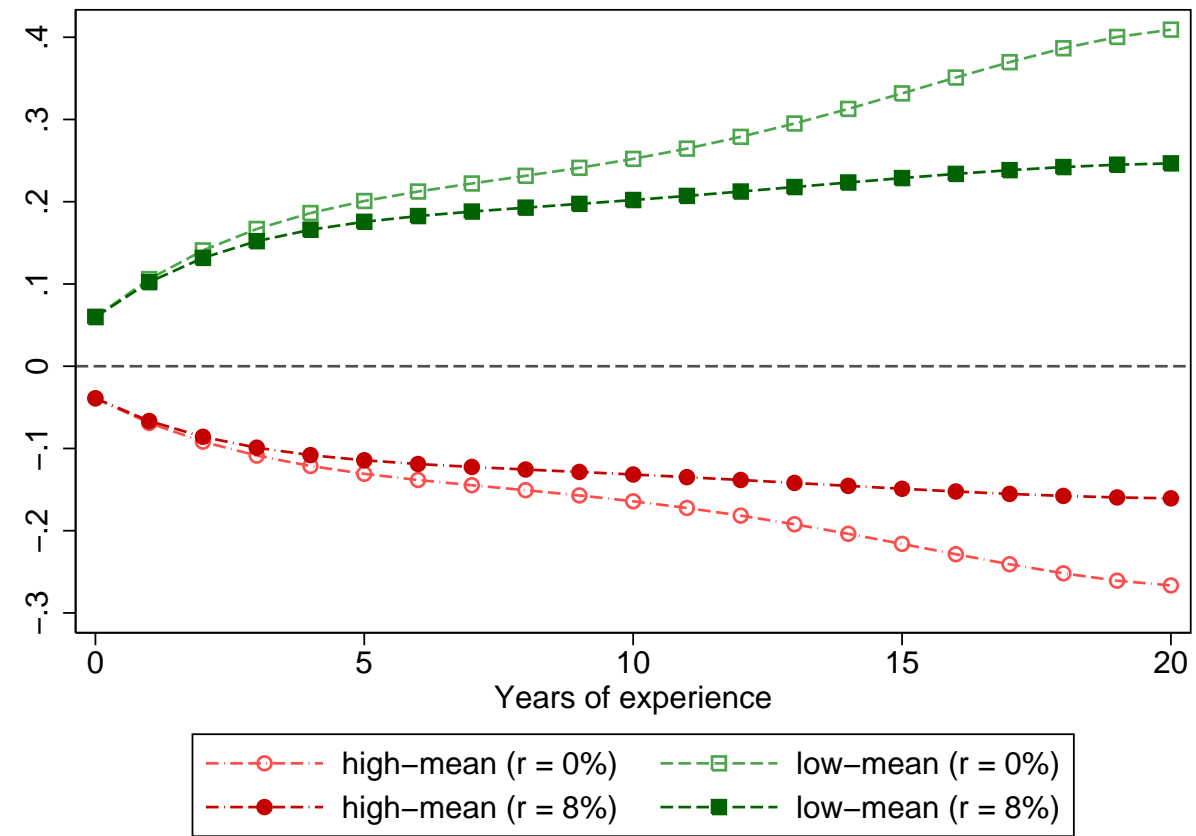

Notes: The dotted red (squared green) line shows accumulated losses (gains) of a hypothetical cohort entering at a high (low) initial unemployment rate, relative to a cohort entering at the average unemployment rate. The dark-shaded lines show the present discounted value of accumulated losses (gains) after $k$ years of labor market experience, using a real interest rate of $8 \%$. See main text for details. 
Figure 6: Taking sample selection over the business cycle into account

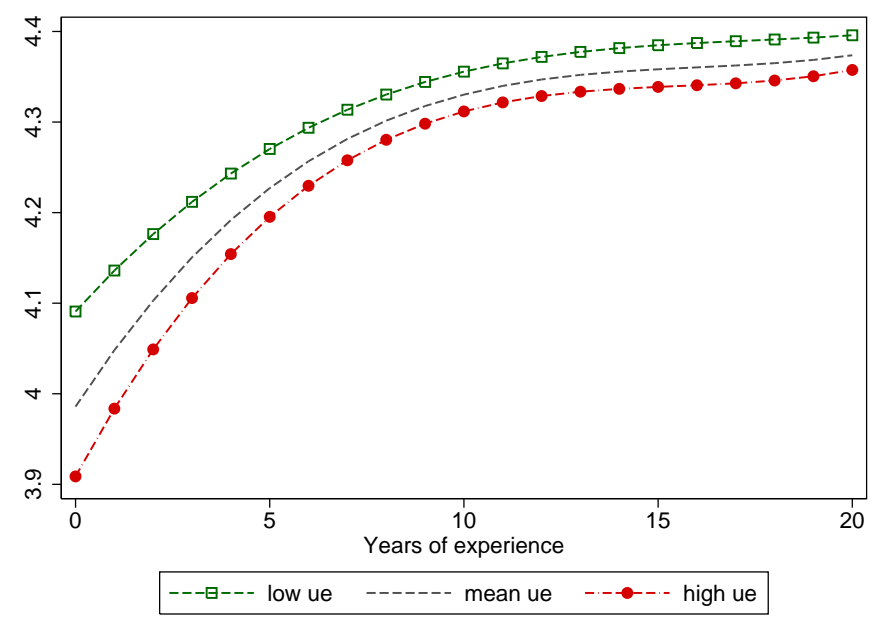

(a)

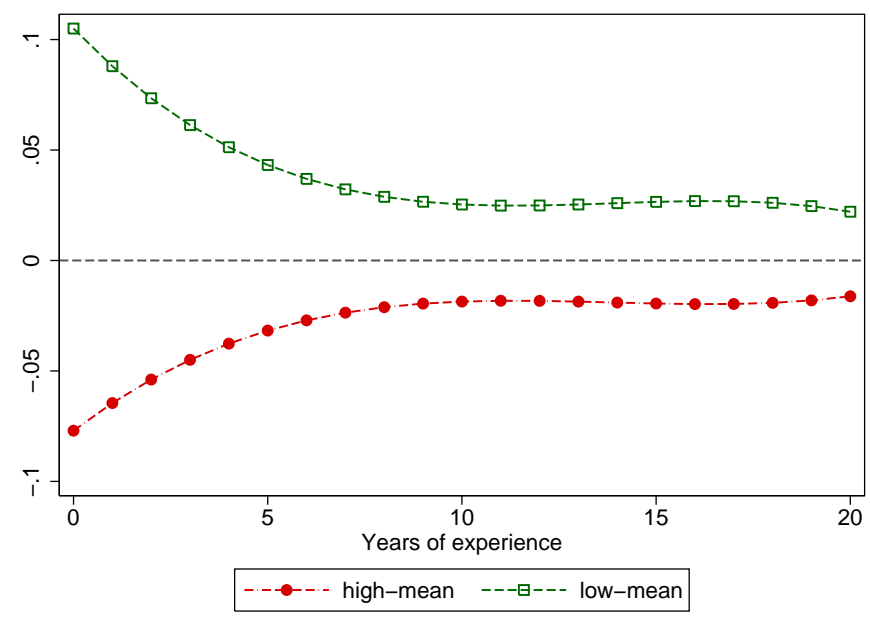

(b)

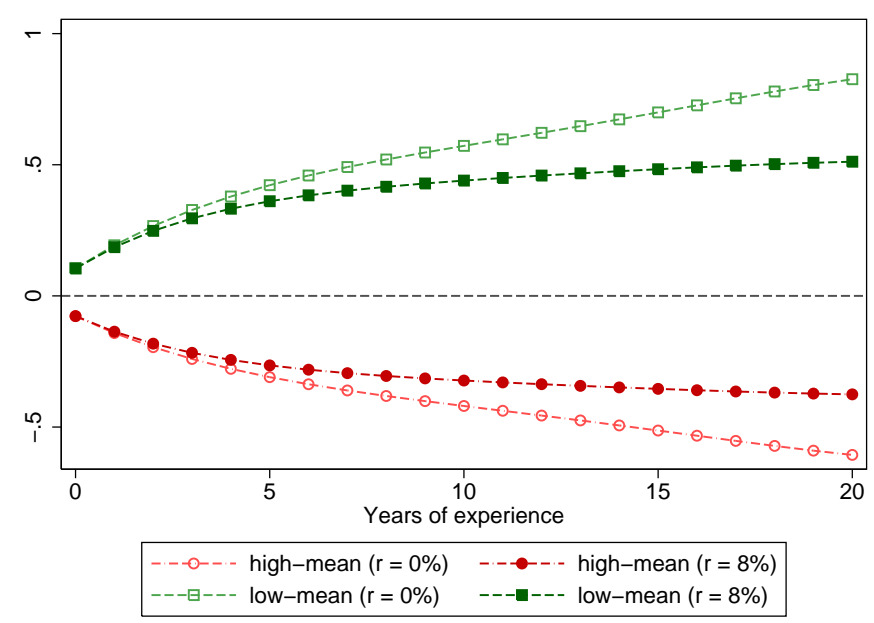

(c)

Notes: The figures are based on the estimates shown in column (2) of table 6. See notes of figures 4 and 5 for additional explanations. 


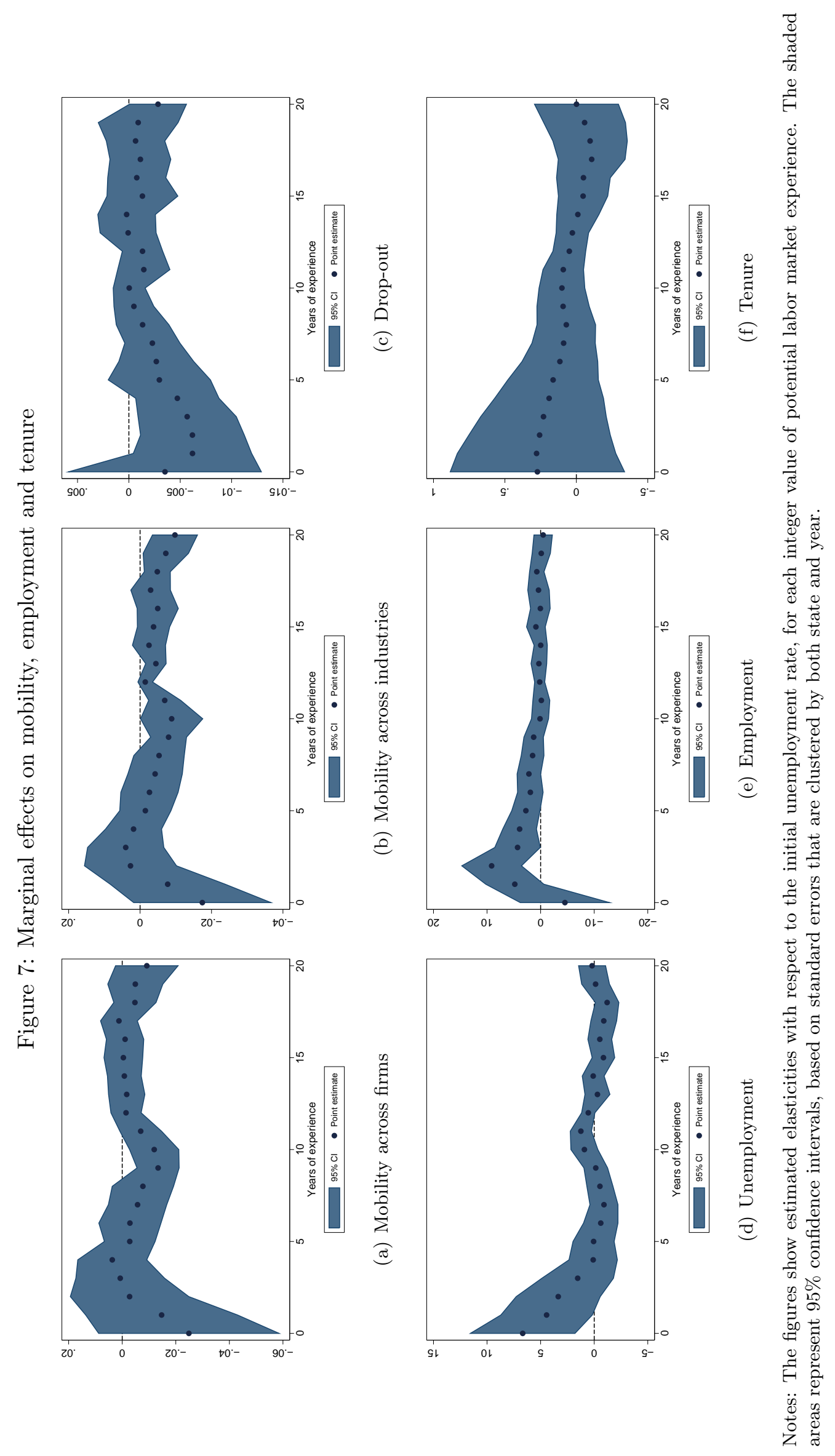


Figure 8: Conditioning on the evolution of mobility, employment and tenure

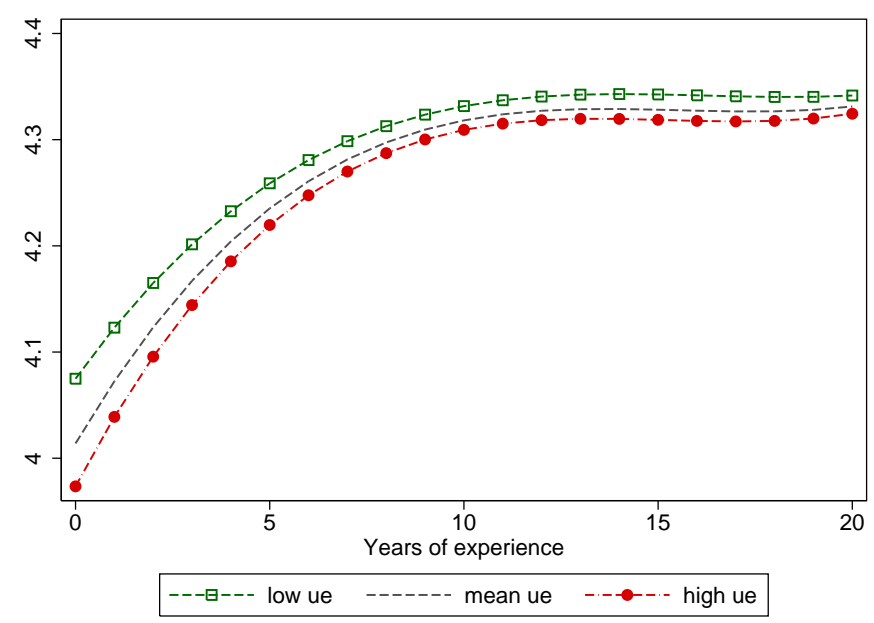

(a)

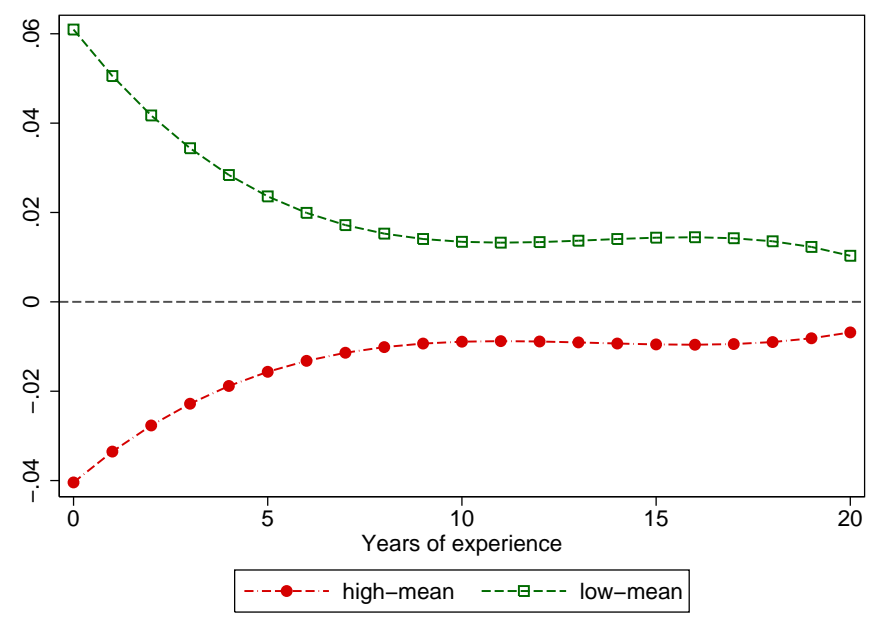

(b)

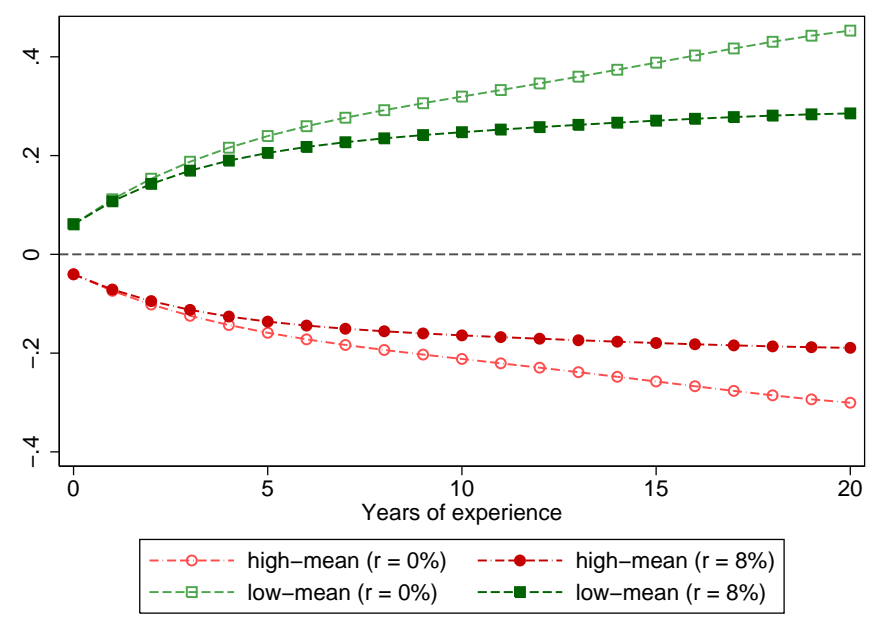

(c)

Notes: The figures are based on the estimates shown in column (3) of table 6. See notes of figures 4 and 5 for additional explanations. 


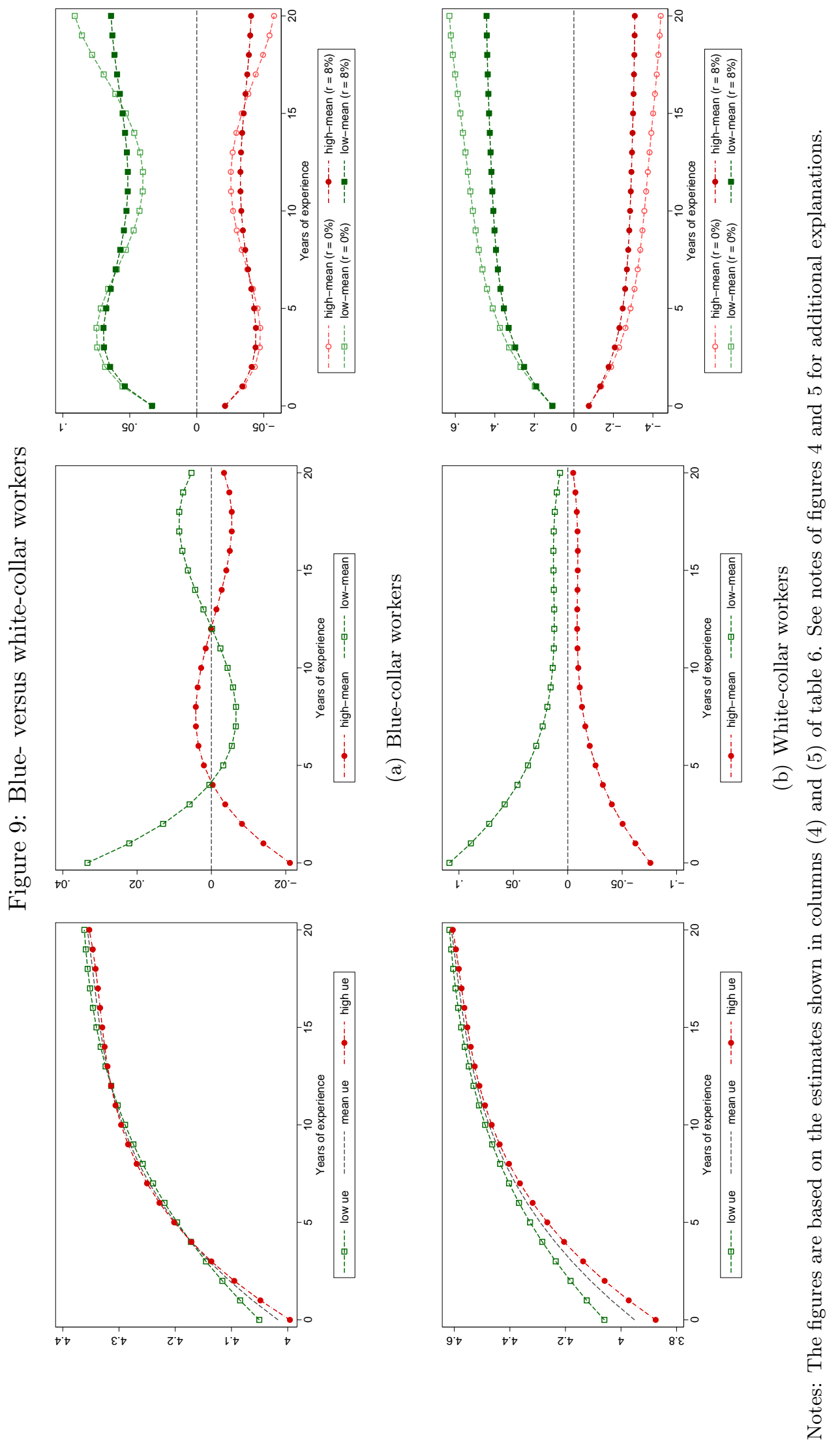


Figure 10: Conditioning on the relative path of current unemployment

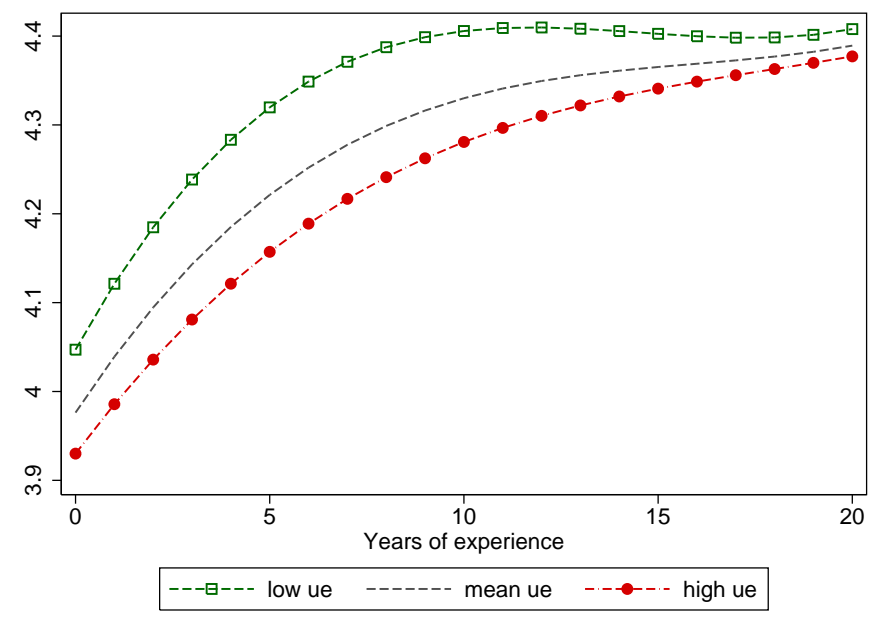

(a)

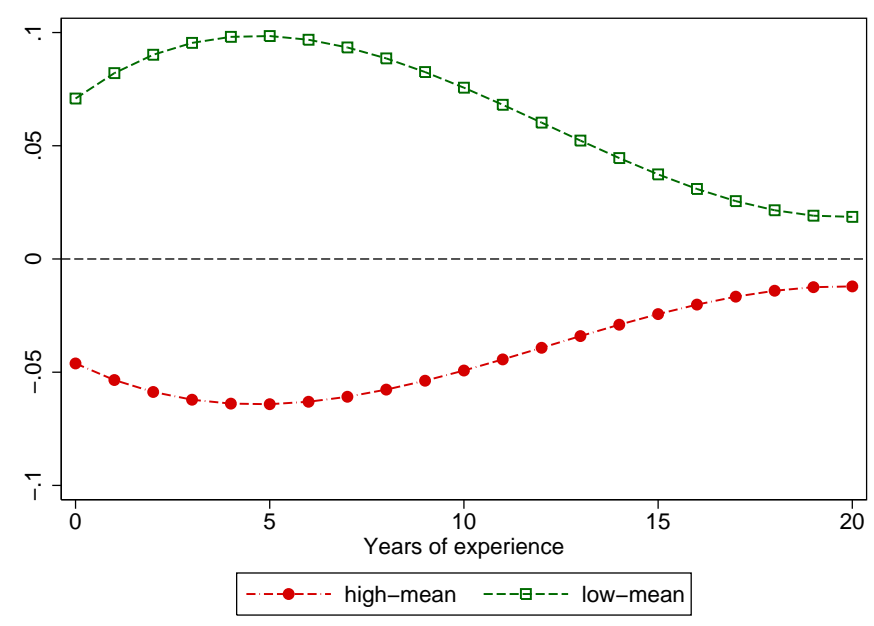

(b)

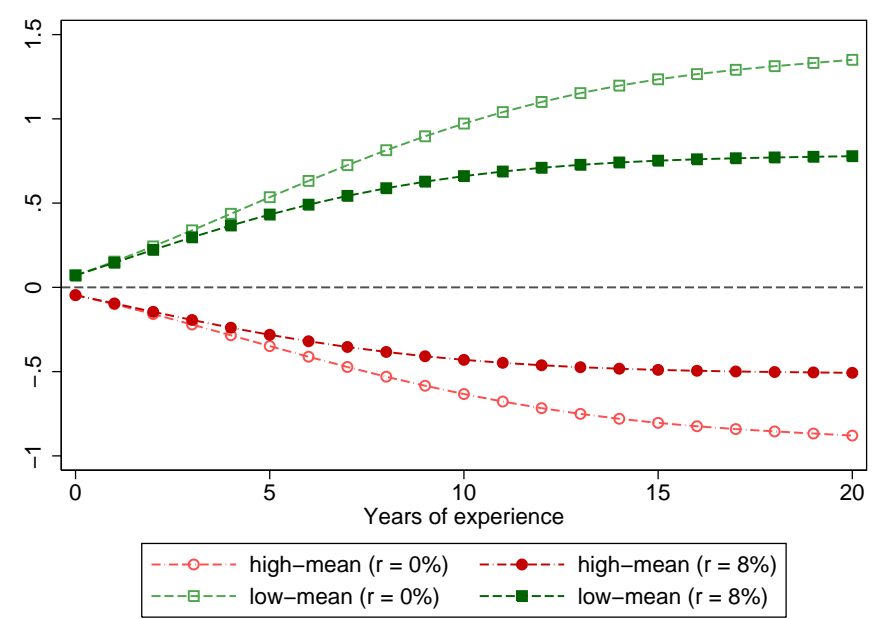

(c)

Notes: The figures are based on the estimates shown in column (6) of table 6 . See notes to figures 4 and 5 for additional explanations. 


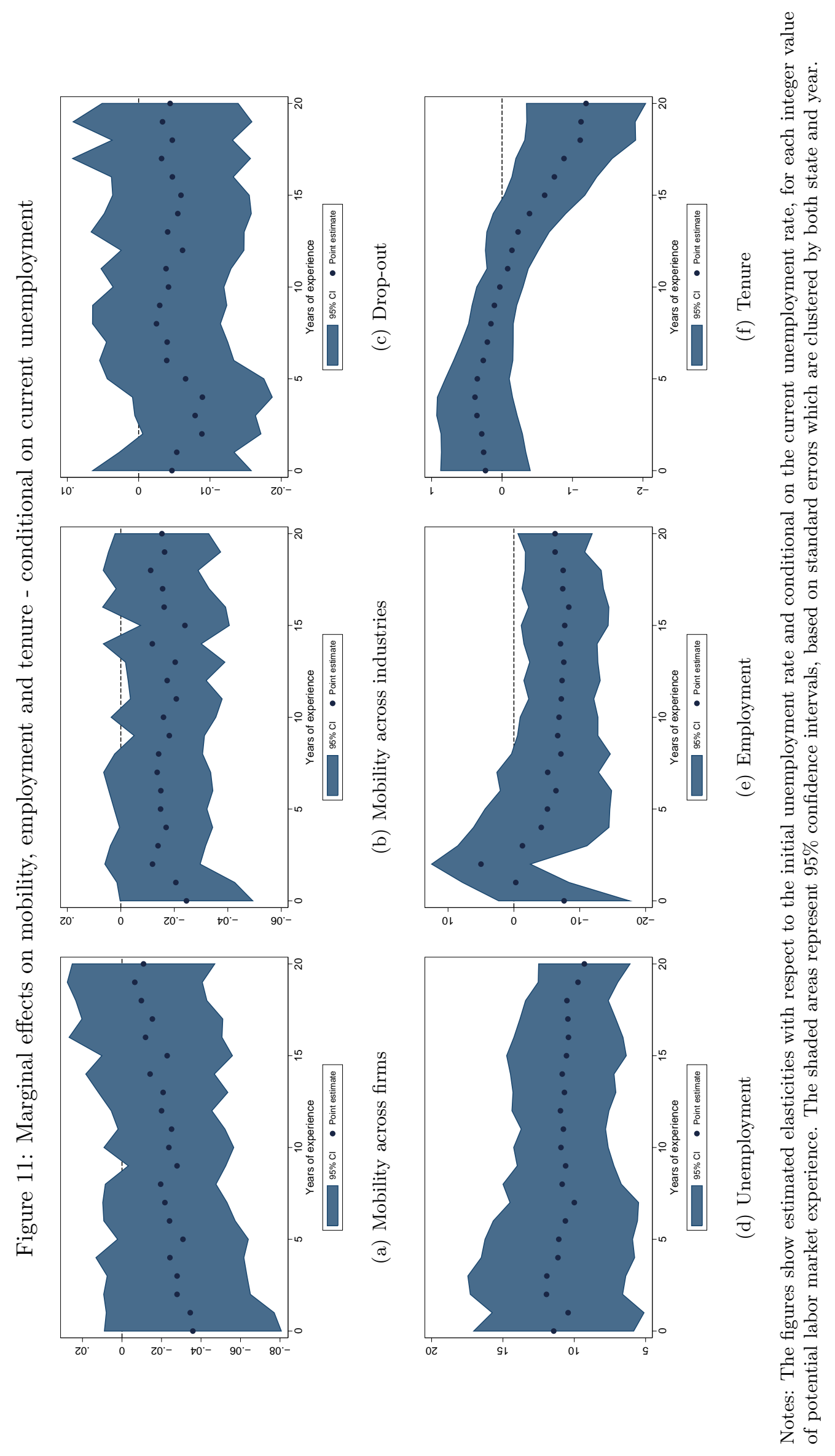




\section{A Data Appendix}

\section{A.1 Sample Construction}

The analysis sample has been constructed in three consecutive steps. First, we have determined the start of the first regular employment spell for each individual born between 1958 and 1985. ${ }^{32}$ The restriction with respect to birth year, in combination with the restriction on age at first entry that we apply below, ensures that the potential range of age at entry is the same for each entry cohort considered in the analysis (1978-2000). Additionally, we drop all individuals who have at least once been self-employed and/or have worked as a farmer or as a civil servant, because such employment spells are not consistently covered by the data over the whole period of analysis and/or because earnings are not recorded (in the case of selfemployment). We therefore can not fully observe the employment and/or earnings histories of such individuals. Second, we have determined each individual's age at the start of his or her first regular employment spell starting between 1978 and 2000. We define regular employment as an employment spell which lasts for at least 180 days. We thus consider training (e.g. apprenticeship) not as regular employment. Considering only employment spells with a duration of at least 180 days as regular employment gives us a total of 1,743,866 observations. Finally, as detailed in the main text, we focus on individuals aged between 15 and 21 years at the start of their first regular employment spell. This still leaves us 821,028 unique individuals (see table 1). Because we follow workers from their year of entry until the end of the data in 2005, the resulting number of observations would have been huge. To speed up the computations somewhat, we have taken a simple $30 \%$ random sample from all remaining labor market entrants - without any significant loss in statistical precision. This final step gives us a total of 223,900 unique individuals and 3,455,396 observations (= individuals $\times$ years) when following these individuals over time.

\section{A.2 Key Variables}

The Central Social Security Administration collects the data for the administration and calculation of old-age pension benefits. The ASSD thus includes very precise and comprehensive information about annual earnings and employment histories on a daily basis as (for details, see Zweimüller et al., 2009). However, contributions to the old-age pension system are capped from above because there is a maximum level of old-age pension benefits. Annual earnings are therefore right-censored, i.e. earnings are recorded only up to the threshold which guarantees the maximum benefit level ("Höchstbemessungsgrundlage", HBGr) as any wage information on top is of no interest to the Social Security Administration. Similarly, there is also a lower threshold below which no social security payments accrue at all ("Geringfügigkeitsgrenze", GfGr). The two censoring points vary over time in real terms: The lower censoring point has increased from about $14 €$ in 1978 to about $26 €$ in 2005 , per day worked. For the same two years, the upper censoring point has increased from about $78 €$ and $126 €$ per workday.

\section{Wages}

All wages are given in prices of 2007 , deflated with the consumer price index ("Verbraucherpreisindex"), and include additional/special payments like, for example, a 13th month of payment. Real daily starting wages refer to the first regular employment spell only. That is, earnings from this first employment spell are divided by the number of days worked in this

\footnotetext{
${ }^{32}$ Obviously, to be included in the sample, an individual must be covered by the ASSD. To be covered, an individual must be entitled to future social security benefits or must already have claimed social security benefits.
} 
specific job in the year of entry. Real daily wages (i.e. wages per day actually worked), on the other hand, are computed as average earnings over all employers in a given year. That is, we first sum total annual earnings over all employers for any individual. We then divide overall earnings by the total number of days worked in a given year, also summed over all employers for a given individual and taking into account overlapping employment spells. In order to add any firm characteristics to observations from individuals who are connected with more than a single employer within a given year, we had to decide on a primary employer for each person-year combination. We decided to use the firm information from the employment relationship with the longest duration in a given year. All firm characteristics in the analysis therefore relate to the primary employer only. In most cases, there is actually no ambiguity with respect to the primary employer anyway.

\section{Unemployment Rates}

In principle, we can compute unemployment rates at any desired level of aggregation from the raw data from the ASSD, as the data contain comprehensive data on individuals' daily employment histories as well as spells of registered unemployment for the relevant population. It is therefore straightforward, albeit somewhat time-consuming, to compute unemployment rates at different levels of longitudinal or regional aggregation and for different age groups. We finally decided to compute the following four unemployment rates: (i) Annual male unemployment rate for the age group 15 to 65 at the level of the state, (ii) annual male unemployment rate for the age group 15 to 25 at the level of the state, (iii) annual male unemployment rate for the age group 15 to 65 at the level of the district, (iv) annual male unemployment rate for the age group 15 to 25 at the level of the district. In all four cases, annual rates are computed as simple averages of monthly rates within any given year and for all years from 1978 until 2005 .

\section{Schooling}

As mentioned in the text, there is no comprehensive schooling measure in the ASSD. For that reason we use individuals' age at the start of their first regular employment spell (as defined above) as proxy for their schooling. As some individuals may claim unemployment benefits before they start their first regular employment, we also computed individuals' age when starting their first spell of registered unemployment, and we then used the minimum of these two variables as an alternative proxy for schooling ('age at first entry'). It turns out that there is no big difference between the two measures. We are well aware that both measures are only imperfect proxies for educational attainment, at least for highly skilled workers. On the other hand, however, the proxies seem to work surprisingly well in practice. For example, the estimated returns to education in the regression models from table B.1 not only have the expected sign, but they also all have a meaningful size troughout. 


\section{B Results for Starting Wages}

In this appendix, we show our main results for starting wages. We estimate the short-run effects of the initial local labor market conditions on individual starting wages using regression models of the following form:

$$
\ln \left(y_{i}^{0}\right)=\ln \left(u r_{j[i]}^{0}\right) \alpha+x_{i} \beta+\psi_{j}+t_{i} \gamma_{j}+\epsilon_{i}
$$

where $y_{i t}^{0}$ is the starting wage of individual $i$ starting his first regular employment in year $t$, $u r_{j[i] t}^{0}$ denotes the unemployment rate prevailing in state $j$ and year $t$. Vector $x_{i t}$ contains individual-level characteristics, e.g. age at first entry into the labor force and two dummy variables indicating broad occupation, and firm-specific characteristics (number of employees, the fraction of the workforce within a firm which is female, the region ("Bundesland") and industry of the firm). Moreover, as cohort size changes quite strongly over the period considered in our analysis, we also include the log of the absolute number of labor market entrants aged 15 to 21 in a given year and state as regressor. Additionally we include a set of state dummies $\psi_{j}$ and state-specific quadratic time trends, i.e. $t_{i}$ includes both calendar year and its square. Of main interest is $\alpha$, which corresponds to the elasticity of the starting wage with respect to the initial unemployment rate. Standard errors are clustered on the state $\times$ year cells throughout to account for the group-level nature of our key regressor.

\section{Table B.1}

Our results with respect to the effect of the local unemployment rate on starting wages are shown in table B.1. The model shown in column 1 does only include a set of state-dummies along with state-specific quadratic time trends. The estimated elasticity of starting wages with respect to the initial unemployment rate equals -0.074 and is very precisely estimated, the clustering of standard errors nonetheless. We add our proxy for schooling (i.e. age at first entry) and two occupational indicators in the second column. This makes the point estimate more negative, yielding an elasticity of starting wages with respect to the initial unemployment rate of -0.097 . The model in column 3 adds various variables which relate to the employer, i.e. size of the firm, the share of the workforce that is female, industry affiliation, and an indicator for whether the firm is a seasonal firm or not. Adding these variables yields almost the same point estimate as before (-0.100). In the fourth column, we add the log of the number of labor market entrants as additional regressor. This model yields a point estimate of -0.129 . The fifth column uses the level of the initial unemployment rate instead of its log as key regressor, yielding a point estimate of -0.018 . We can re-express this estimate as an elasticity as to make it comparable to the other estimates. At the sample mean, doubling the initial unemployment rate implies an elasticity of about $-0.118(=-0018 \cdot 6.55)$ and thus is very similar to the results which use the $\log$ of the initial unemployment rate as regressor. The second to last column adds the square of the log initial unemployment rate as additional regressor. This additional term turns out to be small and statistically insignificant. The last column uses the level of the initial unemployment rate and its square. Both terms are significant in this case, implying that there is some non-linearity in the relation between wages and unemployment. This leads us to think that using the log of the initial unemployment rate is an appropriate and parsimonious model specification.

How do our results compare to published estimates of the elasticity of wages with respect to labor market conditions? Winter-Ebmer (1996) reports elasticities ranging from -0.02 to -0.07 whereas Blanchflower and Oswald (1990) report a range of elasticities of about -0.12 to -0.16. The average estimate for Austria reported in Nijkamp et al. (2005) equals -0.068. In comparison, our estimates are thus much larger than previous estimates for Austria. 
However note that our study focuses on new labor market entrants only, whereas studies on the wage-curve in general estimate the wage elasticity of all workers. This may rationalize that we find effects that are quite a bit larger than the average estimate for Austria reported by Nijkamp et al. (2005) because we think that starting wages are more elastic than incumbent workers' wages. 


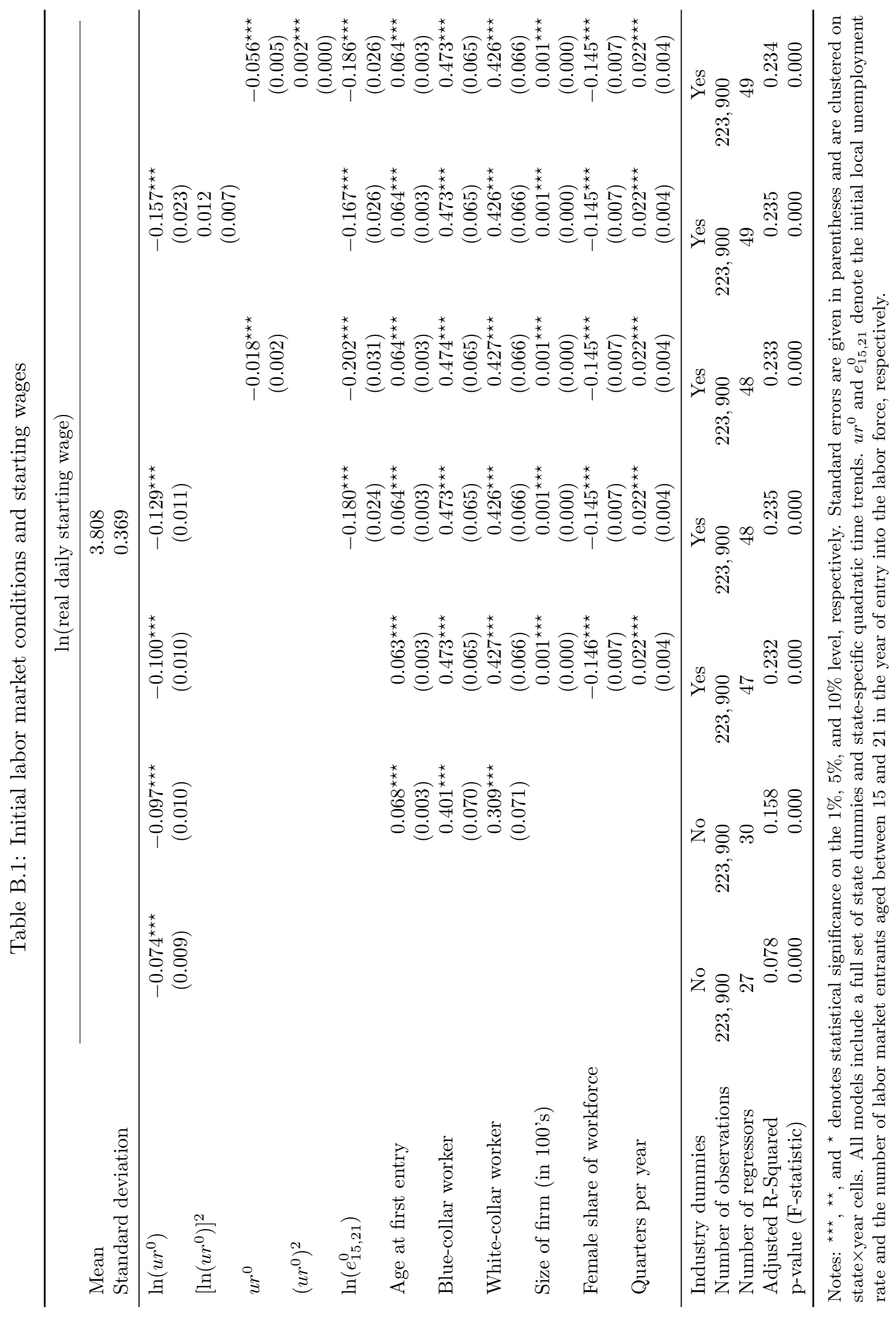




\section{Sample Selection Over the Business Cycle}

In this appendix, we provide some additional evidence with respect to sample selection over the business cycle.

\section{C.1 Delayed Entry into the Labor Force}

We first look at the association between the aggregate number of labor market entrants and the unemployment rate. The estimated elasticity of the number of entrants with respect to the unemployment rate tells us something about the immediate impact of the business cycle on employment. However, note that the reported effect is a mixture of a permanent effect on non-participation, an effect of prolonged duration of schooling and an effect on delayed entry into the labor force. We regress regress the log of the number of labor market entrants on the contemporaneous unemployment rate:

$$
\ln \left(e_{j t}\right)=\ln \left(u r_{j t}\right) \alpha+\ln \left(c s_{t}\right) \beta+\psi_{j}+t_{j} \gamma+\epsilon_{j t},
$$

where $e_{j t}$ and $u r_{j t}$ correspond, respectively, to the absolute number of labor market entrants aged 15 to 21 when first entering into the labor force and the unemployment rate in state $j$ and year $t$. We also include the underlying cohort size $c s_{t}$, which presumably is one of the key determinants of the number of actual labor market entrants. ${ }^{33}$ We further include a set of state dummies, denoted by $\psi_{j}$, and a quadratic time trend, denoted by $t_{j}$. We are interested in the elasticity of the number of labor market entrants with respect to the unemployment rate, which is given by parameter $\alpha$. Results are given in table C.1.

\section{Table C.1}

The first column of table C.1 shows that the raw elasticity of the number of entrants aged 15 to 21 and the current unemployment rate is -0.086 . Adding cohort size does not change the point estimate by much, as shown by the second column. The third column adds state dummies and a quadratic time trend as regressors. This yields a estimated elasticity of -0.132 , quite a bit larger than the first two estimates. Also, note that log cohort size has the expected positive sign now (as opposed to the model in column 2). Using the level of initial unemployment yields very similar results in terms of elasticity, and functional form is thus not important. The right panel of table C.1 shows analogous estimates using the log number of entrants aged between 22 and 30 as dependent variable. Looking at the model in the third column, which again includes the log unemployment rate, the log cohort size as well as state dummies and a quadratic time trends yields a point estimate of -0.287. As expected, the elasticity of more skilled workers appear more sensitive to business cycle fluctuations therefore.

Next, we look at the effect of the local unemployment rate on the timing of first entry into the labor force. Because some workers are eligible for unemployment benefits before their first regular employment (e.g. after completion of an apprenticeship training), we can estimate the effect of the initial unemployment rate on the probability of experiencing any unemployment before one's first regular employment spell. Such estimates are informative about delayed entry

\footnotetext{
${ }^{33}$ Because we only observe individuals' actual labor market entry, the potential number of labor market entrants is unknown to us. We therefore approximate this number by the size of the underlying birth cohorts. First, we extract the number of individuals covered by the ASSD for each year of birth. These numbers do not exactly correspond to the actual size of birth cohorts because individuals who will never enter the labor market will not show up at all in the data. However, a comparison between our figures and official numbers shows that we come pretty close to actual cohort size. We then compute the number of potential entrants aged 15 to 21 as a simple weighted average of the corresponding birth cohorts for 1978 until 1997.
} 
and therefore about endogenous timing of labor market entry. To this end, we estimate models of the following form:

$$
u e_{i}^{0}=\ln \left(u r_{j[i]}^{0}\right) \alpha+x_{i} \beta+\psi_{j[i]}+t_{i} \gamma_{j}+\epsilon_{i},
$$

where $u e_{i}^{0}$ is a measure for an individual's unemployment experience before his first regular employment spell, which is either a dummy variable indicating any unemployment or a variable counting the number of unemployment days before the start of one's first regular employment spell. The regressor of key interest is $u r_{j[i]}^{0}$, the unemployment rate prevailing in the year of entry in state $j$. We include additional control variables $\left(x_{i t}\right)$ that are plausibly exogenous at the time of first entry, including broad occupation and age at first entry as our proxy for schooling. ${ }^{34}$ As before, we also include the log number of labor market entrants to control for demographic shifts that may trigger corresponding changes in the unemployment rate. We further include a set of state dummies and allow for state-specific quadratic time trends, denoted by $\psi_{j}$ and $t_{i} \gamma_{j}$, respectively. In all regressions shown, standard errors are adjusted for clustering at the state $\times$ year level.

\section{Table C.2}

Results are shown in the left panel (first four columns) of table C.2. The dependent variable in the first two columns is a dummy variable indicating whether an individual has experienced any unemployment before entering the labor market and corresponds to the number of days spent in registered unemployment before entering the labor market in the following two columns. As regards the individual probability of experiencing an unemployment spell before regular employment, there is a positive and statistically significant effect of the local unemployment rate at the year of entry. The point estimate of the model with full controls is 0.1 , which corresponds to an elasticity of about a third if evaluated at the mean value of the dependent variable $(=0.1 / 0.302)$. Similarly, there is a positive effect of the initial unemployment rate on the number of days spent in registered unemployment, as shown by columns 3 and 4 of table C.2. Again, the model with full controls implies a large elasticity of unemployment duration before first regular employment with respect to the initial unemployment rate. Indeed, evaluated at the mean value of the dependent variable, the elasticity if almost $50 \%$ $(=20.888 / 41.984 \cdot 100 \%)$.

\section{C.2 Schooling Over the Business Cycle}

A more direct test for selection, and one that actually yields information about the sign of selection, looks at average schooling of new entrants over the business cycle. Therefore, the right panel (the last four columns) of table C.2 provide results for regression models with our proxies for schooling as the dependent variable:

$$
\operatorname{age}_{i}^{0}=\ln \left(u r_{j[i]}^{0}\right) \alpha+x_{i}^{0} \beta+\psi_{j[i]}+t_{i} \gamma+\epsilon_{i},
$$

where $\operatorname{age}_{i}^{0}$ is either an individual's age at the start of his or her first regular job or else the age when first entering the labor market, defined as the minimum of age at the start of first regular job and age at the start of first unemployment spell. The variables on the right-hand side are exactly the same as in equation (C.2) before, except that schooling does not show up

\footnotetext{
${ }^{34}$ One might challenge the assumption that occupation and industry of first regular employment are exogenous in equation (C.2). However, as most of the workers in our sample presumably have completed an apprenticeship, it seems reasonable to treat both broad occupation and industry as exogenous.
} 
as regressor. Parameter $\alpha$ signifies whether there is positive or negative selection as a result of a high local unemployment rate. Results are given in right panel of table C.2.

\section{Table C.2}

It turns out that, whichever of the two dependent variables is used and independent of the exact model specification, the estimated marginal effect of the local unemployment rate with respect to schooling is always significantly positive, showing that the sample of entrants is positively selected in times of high unemployment. Because we expect a negative effect of the initial unemployment rate on wages, the effect of selection runs counter and therefore we should get a downward biased (i.e. a lower bound on the) effect of unemployment using the selected sample only. At the same time, note that the estimated effect of the initial unemployment rate on schooling is quite small throughout: it lies somewhere between about 0.018 and 0.028 (again, evaluated at sample means). 


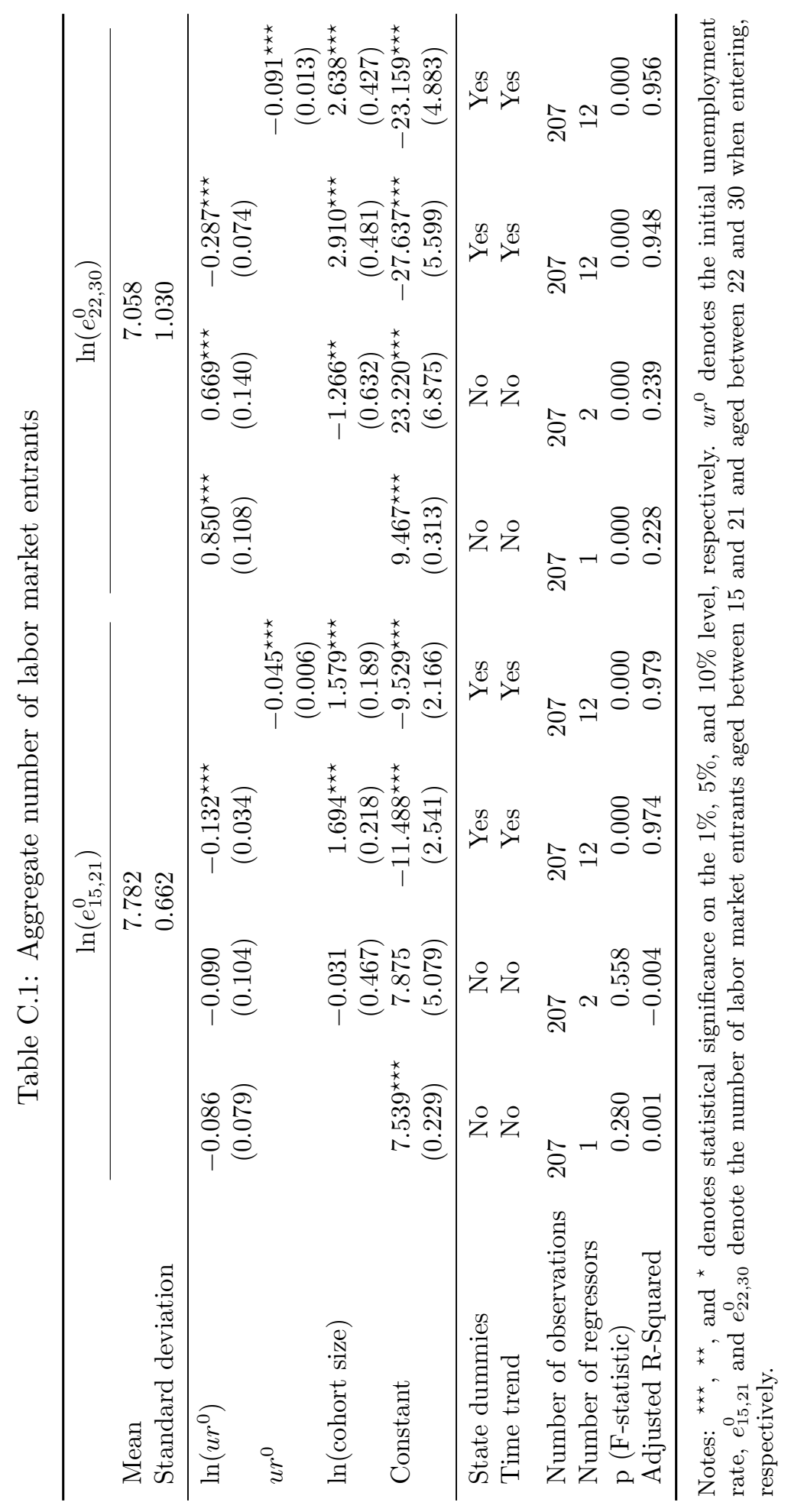




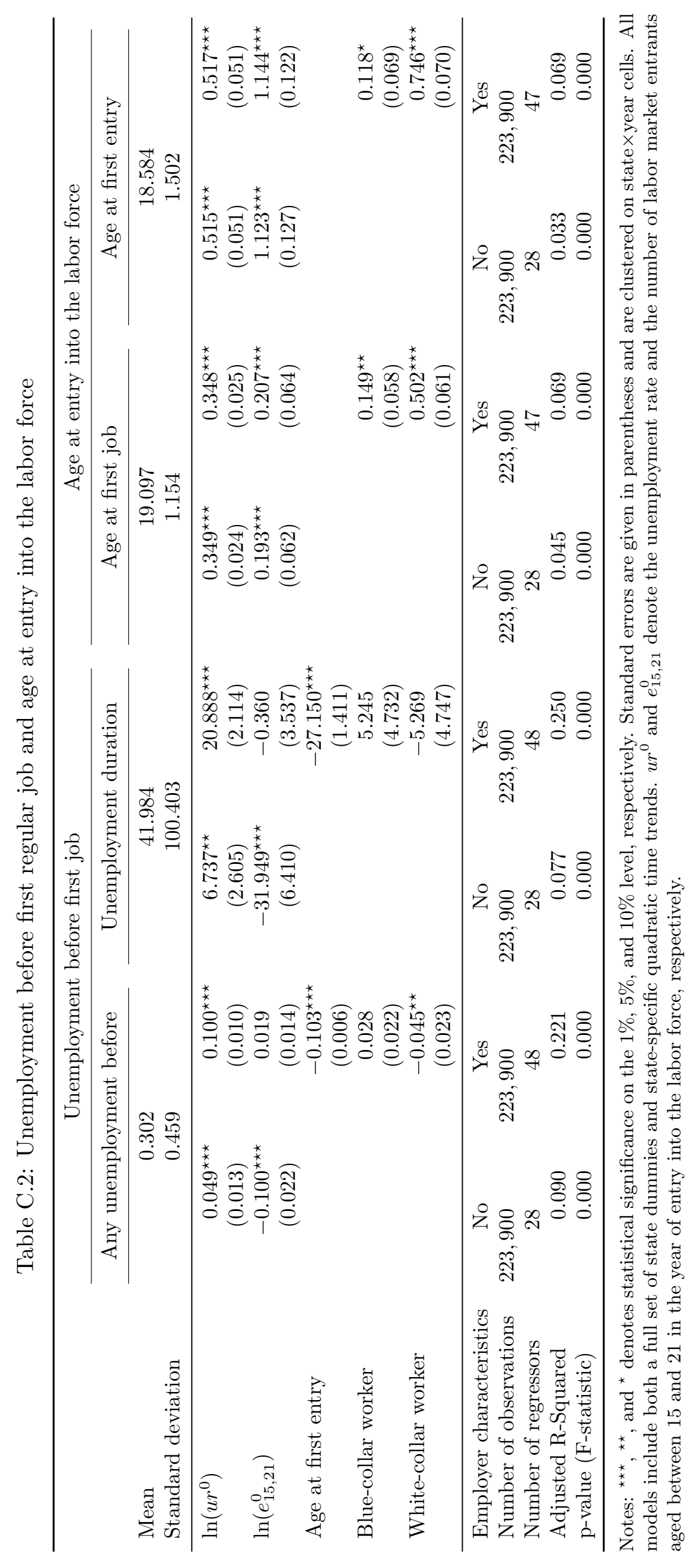

